\title{
Season-dependent predictability barrier for two types of El Niño revealed by an approach to data analysis for predictability
}

\author{
Meiyi Hou ${ }^{1} \cdot$ Wansuo Duan $^{2,3} \cdot$ Xiefei Zhi $^{1}$
}

Received: 4 March 2019 / Accepted: 1 July 2019 / Published online: 6 July 2019

(c) The Author(s) 2019

\begin{abstract}
The real-time prediction skill for El Niño-Southern Oscillation has not improved steadily during the twenty-first century. One important reason is the season-dependent predictability barrier (PB), and another is due to the diversity of El Niño. In this paper, an approach to data analysis for predictability is developed to investigate the season-dependent PB phenomena of two types of El Niño events by using the monthly mean data of the preindustrial control ("pi-Control") runs from several coupled model outputs in CMIP5 experiments. The results find that predictions for Central Pacific El Niño (CP-El Niño) suffered from summer PB, whereas those for Eastern Pacific El Niño (EP-El Niño) are mainly interfered with by spring PB. The initial errors most frequently causing PB for CP- and EP-El Niño are revealed and they emphasize that the initial sea temperature accuracy in the Victoria mode (VM) region in the North Pacific is more important for better predictions of the intensity of the CP-El Niño, whereas that in the subsurface layer of the west equatorial Pacific and the surface layer of the southeast Pacific is of more concern for better predictions of the structure of CP-El Niño. However, for EP-El Niño, the former is indicated to modulate the structure of the event, whereas the latter is shown to be more effective in predictions of the intensity of the event. Obviously, for predicting which type of El Niño will occur, more attention should be paid to the initial sea temperature accuracy in not only the subsurface layer of the west equatorial Pacific and the surface layer of the southeast Pacific but also the region covered by the VM-like mode in the North Pacific. This result provided guidance aiming at how to initialize model in predictions of El Niño types.
\end{abstract}

\section{Introduction}

The El Niño-Southern Oscillation (ENSO) phenomenon represents the strongest interannual climate fluctuation on earth, alternating between warm (El Niño) and cold (La Niña) conditions, which influences weather and climate on a

Wansuo Duan

duanws@lasg.iap.ac.cn

$\triangle$ Xiefei Zhi

xf_zhi@163.com

1 Collaborative Innovation Center on Forecast and Evaluation of Meteorological Disasters (CIC-FEMD)/Key Laboratory of Meteorological Disasters, Ministry of Education (KLME), Nanjing University of Information Science and Technology, Nanjing 210044, China

2 State Key Laboratory of Numerical Modeling for Atmospheric Sciences and Geophysical Fluid Dynamics (LASG), Institute of Atmospheric Physics, Chinese Academy of Sciences, Beijing 100029, China

3 University of Chinese Academy of Sciences, Beijing 100049, China global scale (Bjerknes 1968; Rasmusson and Wallace 1983; Ropelewski and Halpert 1987; Mcphaden et al. 2006). It can exert tremendous climate impacts and even cause severe disasters over the globe, including floods, droughts and storms, which would cause damage to human society and economy (Storlazzi and Griggs 1998; Andrews et al. 2004; Chou and Lo 2007; Zhang et al. 2016). Thus, useful ENSO forecasts are crucial to reduce disasters.

Great progress has been made in understanding ENSO dynamics and physics in recent decades (Neelin 1991; Jin 2000; Levine and Jin 2010; Wang 2018). However, the skill of real-time predictions for ENSO has not improved steadily and has even decreased during the twenty-first century (Barnston et al. 2012; Tang et al. 2018). Taking the 14/16 El Niño events for example, a large El Niño was predicted by several Climate Prediction Centers based on model forecasts from June 2014 initial conditions. However, subsequently, the trade winds and sea surface temperature (SST) conditions changed unexpectedly so that only a considerably weak El Niño occurred in 2014. Based on model forecasts with initialization in December 2014, it was claimed that the 
weakly warm conditions would die out in early boreal spring in 2015. However, the warm SST anomaly intensified rapidly during spring and summer and was maintained all along, finally leading to the strong 15/16 El Niño event (McPhaden 2015). It is thus clear that ENSO forecasts remain elusive.

ENSO is generally thought of as an internal self-sustained dynamic system, which allows for its prediction ahead of its boreal winter peak (Zebiak and Cane 1987; Jin et al. 1994; Chen et al. 2004). However, ENSO prediction currently has skill only within half a year in advance; moreover, considerable uncertainties remain. A major difficulty lies in the so-called "spring predictability barrier" (SPB) occurring in ENSO forecasting (Webster and Yang 1992; Webster 1995; Zheng and Zhu 2010). From a statistical perspective, the SPB is described as an apparent decrease in the anomaly correction coefficient (ACC) between predicted and observed Niño SSTA in the boreal spring (Webster and Yang 1992; Luo et al. 2005). In terms of error growth, the SPB herein refers to the phenomenon of prominent error growth of ENSO predictions, especially when predictions are made before and throughout the boreal spring (Mu et al. 2007; Duan and Wei 2012).

Most ENSO forecasting models, including statistical models and dynamical models, suffer from SPB. However, the SPB did not occur in all of the predictions for ENSO. That is, the SPB occurs in some predictions but not in all predictions, even if the predictions were all aimed at one El Niño and even using one model (Duan and Wei 2012; Qi et al. 2017). As demonstrated in Mu et al. (2007), the SPB results from combined effect of climatological annual cycle, El Niño events themselves, and particular initial error patterns. This finding indicates that, even if climatological annual cycle and El Niño events exist robustly in a model, a particular initial error pattern is necessary to bring about an SPB for ENSO events (Chen et al. 1995, 2004; Xue et al. 1997; Yu et al. 2009; Duan and Wei 2012; Zhang et al. 2015).

A new type of ENSO, referred to as "central Pacific (CP) El Niño", frequently occurred after the 1990s and caused ENSO types to exhibit diversity, being classified into two types, namely, CP-El Niño and EP-El Niño (i.e., the canonical El Niño, referred to as "eastern Pacific (EP) El Niño") (Yu and Kao 2007). The results reviewed in the last paragraph were directly aimed at EP-El Niño events. In fact, the emergence of CP-El Niño has also increased the difficulty of ENSO prediction (Zheng and Yu 2017). The CP-El Niño presents its maximum warming center in the central tropical Pacific, which is different from the EP-El Niño, which presents its maximum warming center in the eastern tropical Pacific. This difference between EP- and CP-El Niño certainly induced different influences on global weather and climate (Ashok et al. 2007; Weng et al. 2007; Zhang et al. 2011, 2012, 2016). In recent years, CP-El Niño has therefore become a hot issue (Larkin and Harrison 2005; Yu and Kao 2007; Kao and Yu 2009; Kug et al. 2009; Lee and Mcphaden 2010; Zheng et al. 2014; Timmermann et al. 2018). In ENSO forecasting, a new aspect of predicting which type of El Niño will occur has attracted more attention. However, the mechanisms governing how CP-El Niño occurs remain controversial. The diversity of the ENSO types and a lesser understanding of CP-El Niño limit the ability of models to simulate and even predict the ENSO events. It has been shown that the useful prediction of El Niño types are around 4 months (Hendon et al. 2009; Jeong et al. 2012). Therefore, it is necessary to investigate CP-El Niño predictability and explore related differences between CP- and EP-El Niño to improve the ENSO prediction skill.

Tian and Duan (2015) traced the evolution of a conditional nonlinear optimal perturbation (CNOP) that acts as the initial error with the largest negative effect on the El Niño predictions by using the Zebiak-Cane model (Zebiak and Cane 1987). They found that for both types of El Niño, their initial errors that have the largest effect on prediction uncertainties are mainly concentrated in the central and eastern tropical Pacific. Furthermore, the CP-El Niño could be erroneously predicted as an EP-El Niño due to the initial errors. However, because the Zebiak-Cane model only covers the tropical Pacific, Tian and Duan (2015) had to focus on the tropical Pacific area to investigate the predictability for the two types of El Niño events. Recent studies have suggested that ENSO could be influenced by extratropical Pacific climate modes, including a Northern Pacific meridional mode and a Southern Pacific one (Vimont et al. 2003a, b; Yu and Kim 2011; Hong and Jin 2014; Zhang et al. 2014; Ding et al. 2015a, b). In addition, Vimont et al. (2001) demonstrated that the mid-latitude atmospheric variability in winter tends to influence the development of positive SST anomalies in the tropical Pacific in the following summer season via a seasonal footprinting mechanism. Yu and Kim (2011) indicated that the North Pacific Oscillation (NPO) could favor the formation of CP-El Niño through weakening the trade winds in the Northern Pacific. Yeh et al. (2015) proposed a hypothesis that a wind-evaporation-SST (WES) feedback mechanism in the northeastern Pacific becomes more effective in initiating the El Niño after 1990, and then CP-El Niño started to become more frequent. It was inferred that the South Pacific Oscillation (SPO) is more responsible for EP-El Niño, also via the WES mechanism (Zhang et al. 2014). In any case, all these studies suggest that extratropical factors may play an important role in the diversity of ENSO types. It is therefore necessary to study the effect of extratropical uncertainties on ENSO predictability.

As reviewed above, the SPB severely limits EP-El Niño event forecasting. That is, EP-El Niño forecasting often suffers from the SPB phenomenon. Then, when investigating the difference between EP- and CP-El Niño events 
in the present study, we naturally ask whether CP-El Niño forecasts also experience a season-dependent predictability barrier (PB). How do the uncertainties from the tropical and extratropical Pacific exert influence on the season-dependent PB for the two types of El Niño events? Additionally, most studies only adopted one numerical model to study ENSO predictability. Then, it is possible that the obtained results are model-dependent. To avoid this limitation, in the present study, we attempt to adopt the data derived from several models in CMIP5, being able to simulate both EP- and CP-El Niño, to find a much more comprehensive result on season-dependent $\mathrm{PB}$ for the two types of El Niño events. In addition to the previously mentioned questions, based on multimodel outputs, we also attempt to identify the initial errors that frequently result in season-dependent PB for the two types of El Niño events. Herein, we use model data to explore the above questions; we further expect to obtain initial errors that result in season-dependent PB. The former is involved with discrete data, whereas the latter is associated with dynamical behavior of error growth. Then, we explore which approach can identify dynamical behaviors from these discrete model data. Herein, we will propose a skillful approach to data analysis for predictability (see Sect. 2) and apply it to several model outputs for studying season-dependent PB for both types of El Niño.

This paper is organized as follows. Section 2 introduces the data we used in this study and explains in detail the approach to data analysis for predictability. Section 3 explores the persistence barriers for the two types of El Niño in CMIP5 models and in observational data. Sections 4 and 5 provide detailed analyses of the predictability barrier for CP- and EP-El Niño events, respectively. Section 6 provides a mathematical interpretation of the evolutionary behavior of initial errors presented in Sects. 4 and 5. Section 7 discusses the implications of the results to El Niño prediction. Finally, Sect. 8 comprises the summary and discussion.

\section{Data and an approach to data analysis for ENSO predictability}

The CMIP5 experiments provide substantial model datasets for scientific studies used in the Intergovernmental Panel on Climate Change (IPCC) Fifth Assessment Report (Taylor et al. 2012). In the present study, we expect to utilize model data to study the initial errors that frequently cause the season-dependent PB of the two types of El Niño events, and outputs from CMIP5 experiments therefore could be a good choice. However, owing to the poor simulation of the CP-El Niño events by numerical models, not all CMIP5 models can capture the main features of both types of El Niño events (Ham and Kug 2012; Kim and Yu 2012; Bellenger et al. 2014). Thus, we have to only choose six models, which can reasonably simulate the two types of El Niño events, referring to the evaluations of Kim and $\mathrm{Yu}$ (2012) and Bellenger et al. (2014). The related configurations and affiliations are listed in Table 1. We analyze preindustrial ("pi-Control") runs of the CMIP5 climate model integrations. Sea surface temperature (SST), ocean subsurface temperature (at depths of 5-155 m), and zonal and meridional wind components are derived from the outputs of the 6 chosen models. To facilitate model intercomparisons and simplify the calculations, only the first 500 years of integration are used, and all the fields are interpolated onto the same grids (i.e., $2.5^{\circ} \times 2.5^{\circ}$ for ocean subsurface temperature and $1^{\circ} \times 1^{\circ}$ for other variables). All the analyses are based on monthly mean data. In addition, anomalies are all computed by removing the monthly climatology mean.

We use the observed monthly mean oceanic dataset HadISST1 (Met Office Hadley Centre Sea Ice and Sea Surface Temperature data) from the Hadley Center (1980-2005, $1^{\circ} \times 1^{\circ}$ ) as the reference (Rayner et al. 2003) to check the persistence of the Niño SSTA of the chosen models.

The pi-Control runs of the CMIP5 outputs, as mentioned above, are adopted in the present study. Therefore, the related $\mathrm{CO}_{2}$ concentration is fixed exactly as $280 \mathrm{ppm}$ for the entire integration period. In other words, the external
Table 1 Six general coupled models from the CMIP5 experiments

\begin{tabular}{llll}
\hline Model & Institute/country & \multicolumn{2}{l}{ Resolution (lon $\times$ lat, vertical) } \\
\cline { 3 - 4 } & & Atmosphere & Ocean \\
\hline CCSM4 & NCAR/USA & $288 \times 192, \mathrm{~L} 26$ & $320 \times 384$, L60 \\
CESM1-BGC & NSF-DOE-NCAR/USA & $288 \times 192, \mathrm{~L} 26$ & $320 \times 384, \mathrm{~L} 60$ \\
CMCC-CMS & CMCC/Italy & $192 \times 96, \mathrm{~L} 95$ & $182 \times 149, \mathrm{~L} 31$ \\
CNRM-CM5 & CNRM-CERFACS/France & $256 \times 128, \mathrm{~L} 31$ & $362 \times 292, \mathrm{~L} 42$ \\
GFDL-CM3 & NOAA GFDL/USA & $144 \times 90, \mathrm{~L} 24$ & $360 \times 200, \mathrm{~L} 50$ \\
GISS-E2-R & NASA GISS/USA & $144 \times 90, \mathrm{~L} 24$ & $288 \times 180, \mathrm{~L} 32$ \\
\hline
\end{tabular}

All related datasets are available online at https://esgf-node.llnl.gov/search/cmip5/, and expansions of the acronyms are available online at http://www.ametsoc.org/PubsAcronymList 
forcing is constant, and the integration results only include effects of the internal variability. Under this circumstance, if we denote a state vector as $\boldsymbol{U}(\boldsymbol{X}, \mathrm{t})=\left[U_{1}(\boldsymbol{X}, t), U_{2}(\boldsymbol{X}, t), \ldots\right.$, $\left.U_{n}(\boldsymbol{X}, t)\right],(\boldsymbol{X}, t) \in \boldsymbol{\Omega} \times[0, T]$, where $t$ denotes time, $T<+\infty$, and $\boldsymbol{X}=\left(x_{1}, x_{2}, \ldots, x_{n}\right)$, then the governing equations for $\boldsymbol{U}$ can be written as follows:

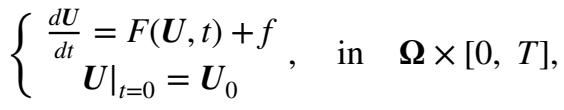

where $\boldsymbol{F}$ is a nonlinear operator, $\boldsymbol{U}_{0}$ is the initial state, and $f$ is an external forcing factor that is a constant and can represent the fixed $\mathrm{CO}_{2}$ concentration in the pi-Control runs. Equation (1) can also be rewritten as follows:

$d \boldsymbol{U}=\boldsymbol{F}(\boldsymbol{U}, t) d t+f d t$.

Then, the integration equation from times $t_{a}$ to $t_{b}$ $\left(t_{a}<t_{b} \leq T\right)$ is derived as follows:

$$
\begin{aligned}
\int_{t_{a}}^{t_{b}} d \boldsymbol{U} & =\int_{t_{a}}^{t_{b}} \boldsymbol{F}(\boldsymbol{U}, t) d t+\int_{t_{a}}^{t_{b}} f d t \\
& =\int_{t_{a}}^{t_{b}} \boldsymbol{F}(\boldsymbol{U}, t) d t+f\left(t_{b}-t_{a}\right) .
\end{aligned}
$$

From Eq. (3), it is easily known that for a future time $t_{b}$, the corresponding state $\boldsymbol{U}_{t_{b}}$ can be described as follows:

$\boldsymbol{U}_{t_{b}}=\boldsymbol{U}_{t_{a}}+\int_{t_{a}}^{t_{b}} \boldsymbol{F}(\boldsymbol{U}, t) d t+f\left(t_{b}-t_{a}\right)$

where $\boldsymbol{U}_{t_{a}}$ is the value of the state $\boldsymbol{U}$ at time $t_{\mathrm{a}}$, and $\int_{t_{a}}^{t_{b}} \boldsymbol{F}(\boldsymbol{U}, t) d t$ indicates that the operator is integrated during $\left[t_{a}, t_{b}\right]$. From the pi-Control run adopted in the present study, we pick two time periods $\left[t_{01}, t_{1}\right]$ and $\left[t_{02}, t_{2}\right]$ with their respective initial states, denoted by $\boldsymbol{U}_{t_{01}}$ and $\boldsymbol{U}_{t_{02}}$, and final states $\boldsymbol{U}_{t_{1}}$ and $\boldsymbol{U}_{t_{2}}$ (see Fig. 1). Because the pi-Control runs do not consider time-dependent external forcing and only consist of internal variability, these control runs can be thought of as being governed by Eq. (4). Then, the final states $\boldsymbol{U}_{t_{1}}$ and $\boldsymbol{U}_{t_{2}}$, similar to Eq. (4), can be written as Eqs. (5) and (6) as follows:

$\boldsymbol{U}_{t_{1}}=\int_{t_{01}}^{t_{1}} \boldsymbol{F} d t+\boldsymbol{U}_{t_{01}}+f\left(t_{1}-t_{01}\right)$

$\boldsymbol{U}_{t_{2}}=\int_{t_{02}}^{t_{2}} \boldsymbol{F} d t+\boldsymbol{U}_{t_{02}}+f\left(t_{2}-t_{02}\right)$

If the two time periods possess common lengths, we can take the difference between two final states as in Eq. (7) as follows:

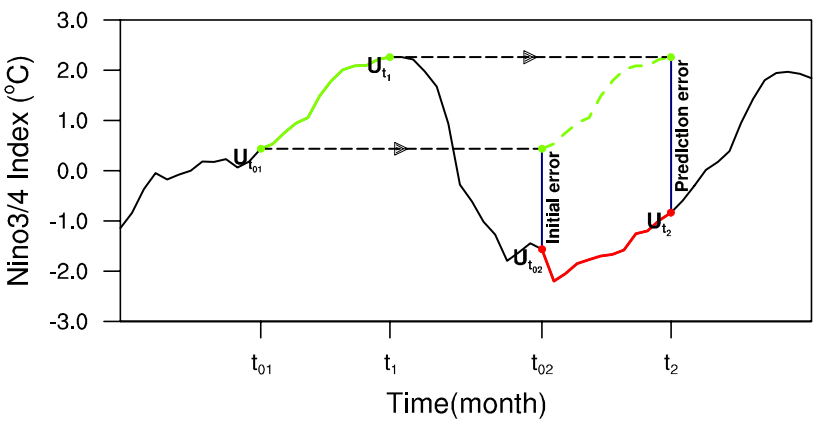

Fig. 1 Schematic diagram of the approach to data analysis for predictability. The black solid curve denotes the time-dependent pi-Control run of SST. Two one-year time periods are picked, as denoted by the green and red curves. The SST time series during the time period $\left[t_{01}, t_{1}\right]$ is moved to fit that during $\left[t_{02}, t_{2}\right]$. If the former SST time series is regarded as an "observation", the latter SST time series can be thought of as a "prediction" of that "observation". The corresponding initial error and prediction error are represented by the SST difference between $t_{02}$ and $t_{01}$ and between $t_{2}$ and $t_{1}$, which are marked by the two navy blue lines

$\boldsymbol{U}_{t_{2}}-\boldsymbol{U}_{t_{1}}=\boldsymbol{U}_{t_{02}}-\boldsymbol{U}_{t_{01}}+\left(\int_{t_{02}}^{t_{2}} \boldsymbol{F} d t-\int_{t_{01}}^{t_{1}} \boldsymbol{F} d t\right)$

The Eq. (7) can be rewritten as the same form as Eqs. (5) and (6):

$\boldsymbol{U}_{t_{2}}-\boldsymbol{U}_{t_{1}}=\boldsymbol{U}_{t_{02}}-\boldsymbol{U}_{t_{01}}+\int_{\Sigma}\left[\boldsymbol{F}_{t_{02}}-\boldsymbol{F}_{t_{01}}\right] \mathrm{d} t$.

Here, $\boldsymbol{F}_{t_{02}}$ is the $\boldsymbol{F}$ in Eq. (6) and $\boldsymbol{F}_{t_{01}}$ is the $\boldsymbol{F}$ in Eq. (5). And $\Sigma$ represents the time interval $\left[t_{01}, t_{1}\right]$ for $\boldsymbol{F}_{t_{01}}$ or $\left[t_{02}, t_{2}\right]$ for $\boldsymbol{F}_{t_{02}}$, which are of the same length. It is easily known from Eq. (8) that the difference between $\boldsymbol{U}_{t_{1}}$ and $\boldsymbol{U}_{t_{2}}$ is only a matter of the initial difference $\boldsymbol{U}_{t_{02}}-\boldsymbol{U}_{t_{01}}$. That is, the difference between $\boldsymbol{U}_{t_{1}}$ and $\boldsymbol{U}_{t_{2}}$ can be thought of as being derived by the model Eq. (4) with initial difference $\boldsymbol{U}_{t_{02}}-\boldsymbol{U}_{t_{01}}$. As illustrated in Fig. 1, if the second time period is moved to fit the first time period, then Eq. (8) can be thought of as a governing equation that describes the evolution of the initial difference $\boldsymbol{U}_{t_{02}}-\boldsymbol{U}_{t_{01}}$, where the difference $\boldsymbol{U}_{t_{2}}-\boldsymbol{U}_{t_{1}}$ is its final result at the end of the time period. Therefore, if the state during the time period $\left[t_{01}\right.$, $\left.t_{1}\right]$ is referred to as an "observation", the state during the second time period $\left[t_{02}, t_{2}\right]$ can be regarded as the "prediction" of the "observation" by shifting and superimposing it on the first time period. In addition, the "prediction" errors, as shown in Eq. (8), are only caused by "initial errors" implied by $\boldsymbol{U}_{t_{02}}-\boldsymbol{U}_{t_{01}}$ (see Fig. 1). It should be noted that this data-analysis method can only focus on the variability with a climatological cycle such as annual cycle and diurnal cycle. Since ENSO events are the dominant 
source of interannual climate variability with an annual cycle, the method can therefore be applied to explore the dynamics of ENSO predictability.

With the above consideration, we pick out some typical CP-El Niño years from the 500-year integration of each model as "observations" (Table 2). Because there are only a few typical CP-El Niño events in the 500-year integration in some models, we manage to select 13 typical CP-El Niño events from each model, with warming in early boreal spring and peaking at the end of the year. For comparison, we also select 13 typical EP-El Niño years of each model. For each of these one-year "observations", we pick the corresponding 201 -year periods before and after it, and a total of 40 "predictions" (with a lead time of 12 months) of the "observation" can be obtained. This approach yields 520 predictions for each of the $13 \mathrm{CP}$ - and $13 \mathrm{EP}-\mathrm{El}$ Niño events for each model. Then, the related prediction errors $E(t)$ indicated by $\boldsymbol{U}_{t_{2}}-\boldsymbol{U}_{t_{1}}$ can be expressed as in Eq. (9) as follows:

$E(t)=\sqrt{\frac{1}{N} \sum_{(i, j)}\left[T_{(i, j)}^{p}(t)-T_{(i, j)}^{o}(t)\right]^{2}}$,

where $T^{p}$ represents the "prediction", $T^{o}$ is the "observation", $(i, j)$ denotes the grid points, and $N$ is the total number of grid points in the Niño4 area for CP-El Niño (the Niño3 area for EP El Niño).

To investigate the season-dependent $\mathrm{PB}$ for the two types of El Niño, we use the tendency of the prediction errors, which was proposed by $\mathrm{Mu}$ et al. (2007), to measure the seasonal growth of prediction errors. Exactly, it can be expressed as the slope $\kappa$ of the curve $E(t)$ as follows [see Eq. (10)]:

$\kappa=\frac{\partial E(t)}{\partial t}=\lim _{\Delta t \rightarrow 0} \frac{E\left(t_{0}+\Delta t\right)-E\left(t_{0}\right)}{\Delta t}$.

For the monthly data derived from the model outputs used in the present study, we can take the approximation

Table 2 Numbers of EP- and CP-El Niño derived from the 100year pi-Control run data for six models and corresponding HadISST observations

\begin{tabular}{lcl}
\hline Data & EP El Niño events & $\begin{array}{l}\text { CP El } \\
\text { Niño } \\
\text { events }\end{array}$ \\
\hline CCSM4 & 100 & 65 \\
CESM1-BGC & 102 & 74 \\
CMCC-CMS & 89 & 75 \\
CNRM-CM5 & 138 & 36 \\
GFDL-CM3 & 99 & 82 \\
GISS-E2-R & 83 & 41 \\
HadISST & 118 & 73 \\
\hline
\end{tabular}

$\kappa \approx \frac{E\left(t_{0}+\Delta t\right)-E\left(t_{0}\right)}{\Delta t}$, with $\Delta t$ being 1 month. A positive (negative) value of $\kappa$ corresponds to an increase (decrease) of the errors, and the larger the absolute value of $\kappa$, the faster the increase (decrease) of the error. Then, the growth tendency of prediction errors during one season can be measured by the sum of the three successive monthly slopes $\kappa$ in this season. The largest sum of the three monthly $\kappa$ denotes the season of the largest prediction error growth, which indicates a PB phenomenon occurs in that season.

\section{Persistence barrier of El Niño}

Following Kug et al. (2010), we use Niño3 and Niño4 SSTA [i.e., the SST anomaly averaged over the Niño3 area $\left(150^{\circ} \mathrm{E}-90^{\circ} \mathrm{W}, 5^{\circ} \mathrm{S}-5^{\circ} \mathrm{N}\right)$ and that over the Niño4 area $\left.\left(150^{\circ} \mathrm{E}-90^{\circ} \mathrm{W}, 5^{\circ} \mathrm{S}-5^{\circ} \mathrm{N}\right)\right]$ to measure the intensities of EPand CP-El Niño, respectively. Generally, it is regarded as a typical EP- (CP-) El Niño when the related Niño3 (Niño4) SSTA greater than 0.5 persists at least 6 months and peaks in the boreal winter (NDJ). The PB for ENSO is essentially associated with the persistence barrier in ENSO-related SSTA (Latif et al. 1998; Duan et al. 2009; Ren et al. 2016). The so-called ENSO persistence barrier can be understood as the most rapid loss of SSTA persistence in related areas such as Niño3 or Niño4 areas. Generally, it is measured by the lag autocorrelation of the time series of Niño SSTA. That is, the lag autocorrelation of the SSTA decreases quickly when a persistence barrier occurs. In this section, we therefore investigate what persistence barriers occur in the lag autocorrelations of the Niño3 and Niño4 SSTA.

Figure 2 shows the lag autocorrelations of the Niño3 and Niño4 SSTA derived from the HadISST1 dataset and the predetermined six model outputs. The density of the autocorrelation coefficient contours describes the descending gradient of the lag autocorrelation coefficient for the Niño SSTA. It is easily understood that the denser the lag autocorrelation coefficient contours, the greater the gradients, and the more rapid the decline in the lag autocorrelation coefficients of Niño SSTA. The fastest descent of the autocorrelation coefficients indicates a bad persistence of the Niño SSTA. Therefore, the persistence is the worst when the lag autocorrelation coefficient contours are the densest; in this situation, we think that a persistence barrier occurs. From Fig. 2, it is easily seen that persistence barriers occur in both the Niño3 and Niño4 SSTA derived from the HadISST1 dataset. In particular, for the time series of Niño3 SSTA, the autocorrelation coefficient declines significantly during the late spring and early summer from April to June. However, the autocorrelation of Niño4 SSTA decreases dramatically during the summer season from June to August. Furthermore, the Niño3 SSTA tends to have a stronger persistence barrier than Niño4 SSTA, as measured 


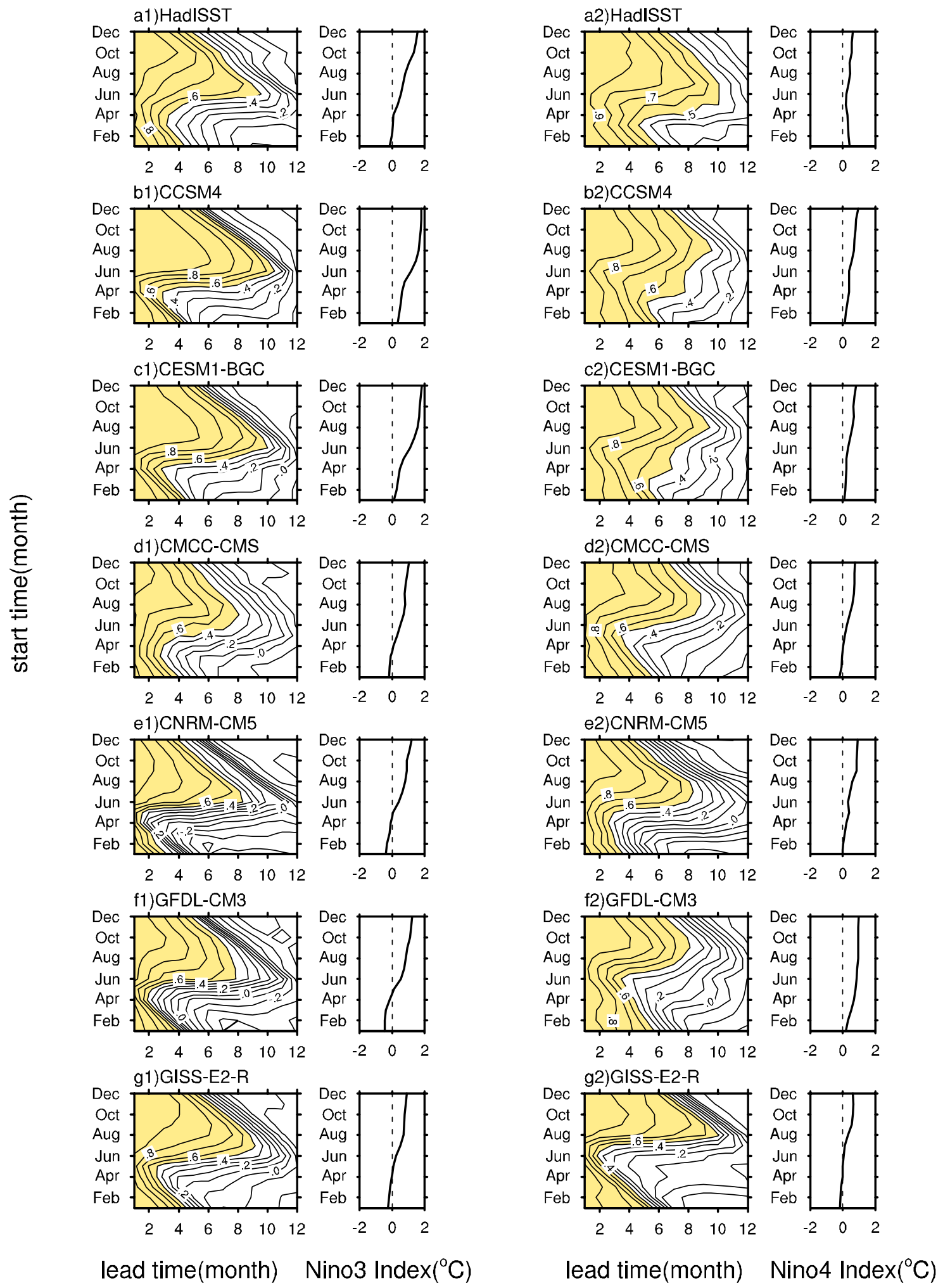

Fig. 2 SST autocorrelation as a function of initial calendar month $(y$-axis) and lag month ( $x$-axis) derived from the pi-Control run of the six models and HadISST1 data (1980-2015). Correlation coefficients exceeding the $95 \%$ significance level are shaded. The contour interval

is 0.1 . The line plots represent the ensemble mean of Niño3/4 index in the EP/CP El Niño year (units are ${ }^{\circ} \mathrm{C}$ ). P(1) is for the EP El Niño events, whereas (2) is for the CP El Niño events 
by the descending gradient of the lag autocorrelation coefficients. To distinguish this difference between Niño3 and Niño4, we consider that a spring persistence barrier exists for Niño3 SSTA and that a summer persistence barrier exists for Niño4. These outcomes indicate that the SSTA associated with EP-El Niño tends to have a spring persistence barrier and that associated with CP-El Niño is inclined to yield a summer persistence barrier.

For the predetermined model outputs, it can be seen from Fig. 2 that all six models' outputs have season-dependent persistence variability in both Niño3 and Niño4 SSTA. For the Niño3 SSTA, the most rapid descent of the lag autocorrelation, similar to that derived from the HadISST1 dataset, occurs during the late boreal spring and early summer, indicating that the model El Niño tends to yield a spring persistence barrier in the Niño3 SSTA. In particular, these predetermined models, except for the CMCC-CMS, present stronger spring persistence barriers than that derived from the HadISST1 dataset in terms of the measurement of the descending gradient of the lag autocorrelation coefficient of the Niño3 SSTA. For Niño4 SSTA, all the models present weaker summer persistence barriers than that derived from the HadISST1. In any case, it can be thought that almost all of these predetermined models feature the seasonality of persistence barriers for Niño3 and Niño4 SSTA shown in observations. Therefore, it is reasonable to use these models to explore the season-dependent PB problems for the two types of El Niño from the perspective of error growth and to distinguish their differences.

\section{The summer PB for CP El Niño and its related initial error growth}

It is known that the persistence of a signal reflects the dynamical behavior of the concerned physical variable. The worst persistence, referred to as a persistence barrier, indicates the most unstable dynamical growth of the signal. The unstable dynamical growth of the signal favors the rapid growth of an error superimposed on the signal (Feng et al. 2014; Duan and $\mathrm{Hu} 2015)$. As mentioned in the introduction, the phenomenon of prominent error growth in ENSO predictions is defined as the predictability barrier (PB). Thus, a PB of ENSO is likely to occur when the ENSO-associated SSTA yields a persistence barrier. In the last section, we find that the SSTA associated with CP-El Niño may yield a summer persistence barrier. Therefore, it is reasonable to speculate that the prediction errors of CP-El Niño may increase most rapidly during summer, which leads to a summer $\mathrm{PB}$ for predictions of CP-El Niño.

To verify this speculation, we manage to explore the $\mathrm{PB}$ of CP-El Niño events by using the approach described in Sect. 2. From Sect. 2, it is known that each CP-El Niño event has 40 predictions; consequently, a total of 520 predictions are obtained for the selected 13 CP-El Niño in each model. Figure 3 shows the ensemble mean of the monthly growth rates of the Niño4 SSTA component of the prediction errors for the 520 predictions. It is shown that for the predetermined six models, the prediction errors of Niño4 SSTA mainly grow significantly from June to August, which coincides with the time period when the SSTA persistence for the CP-El Niño barrier occurs. Therefore, the CP-El Niño events tend to experience a summer PB when they undergo the time period during which the signal grows most unstably.

Figure 4 illustrates the evolutionary behaviors of prediction errors for the $13 \mathrm{CP}$-El Niño events predictions. It is clear that some predictions have obvious season-dependent evolutions of prediction errors with significant error growth in boreal summer and thus yield significant summer PBs, whereas others show less significant season-dependent evolutions of prediction errors and fail to yield PBs. We also examine the prediction errors for individual CP-El Niño. It is still found that some predictions for it present summer $\mathrm{PB}$, and others do not. It is therefore inferred that particular initial errors are necessary to bring about a summer $\mathrm{PB}$ for CP-El Niño besides the enhancement role of the summer unstable growth dynamics of the SSTA associated with CP-El Niño. Then, which features of the initial errors are more likely to cause summer PB for CP-El Niño events? In addition, how do these initial errors evolve and exert influences on the CP-El Niño predictions?
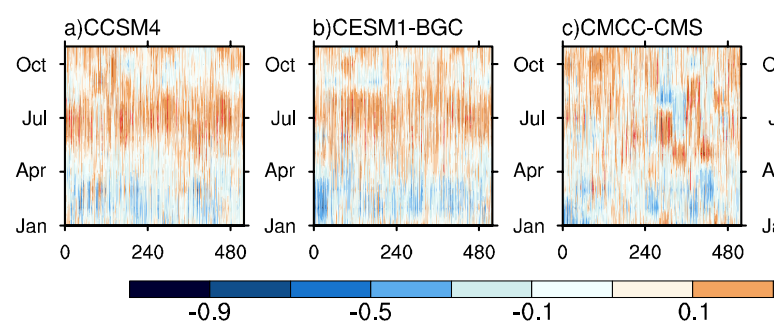

Fig. 3 Monthly growth rates of prediction errors of the Niño4 index for 520 predictions as derived from the pi-Control run of each of the six models. The horizontal axes denote the samples of initial errors, and the vertical axes represent the calendar month. The contour lines

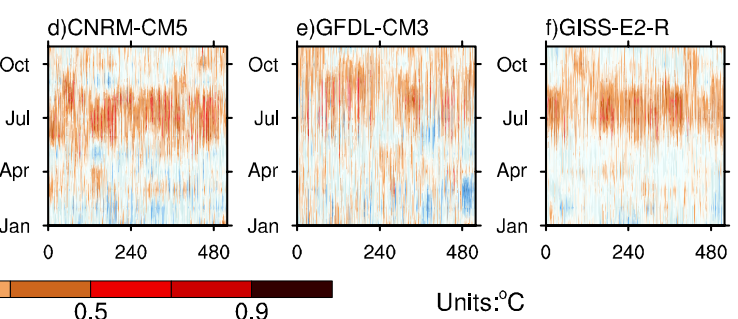

describe the monthly growth rates of the prediction errors. Positive values (red color) denote increases in the prediction errors, whereas negative values (blue lines) denote decreases in the prediction errors 
Fig. 4 The evolution of the prediction errors of the Niño4 index caused by the summer PB-related initial errors (pink shaded) and other initial errors (light blue shaded). The red and blue lines denote the ensemble mean of the evolutions of the summer PB-related initial errors and other initial errors, respectively. The numbers with the letter " $n$ " above each plot represent the numbers of summer PB-related initial errors from all 520 predictions for each model
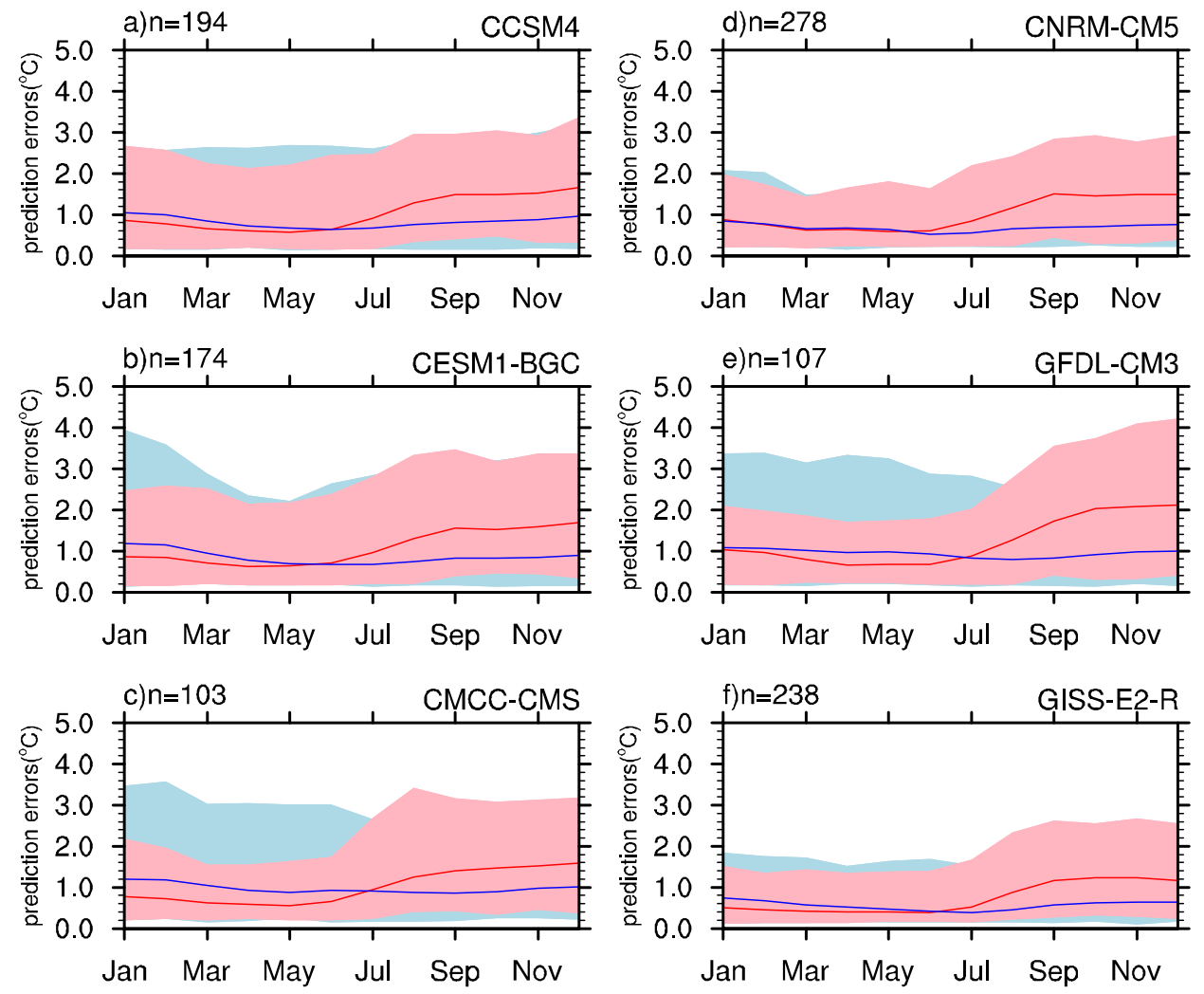

To address these questions, all the predictions that trigger summer PB (hereafter as "summer PB-related predictions") in all the predetermined models are selected. The numbers of the summer PB-related predictions in each model are given in Fig. 4. Then, an Empirical Orthogonal Function (EOF) analysis is applied to their initial errors over the Pacific region $\left[66.5^{\circ} \mathrm{S}-66.5^{\circ} \mathrm{N}, 120^{\circ} \mathrm{E}-70^{\circ} \mathrm{W}\right]$. The first three EOF modes (which explained approximately $35 \%$ of the total variances of the initial errors for each model) are chosen, and the initial errors highly correlated with these three EOF modes are selected. Here, for each EOF mode, if the Principle Component (PC) value is larger than the mean of the positive $\mathrm{PC}$ for all summer PB-related initial errors, it can be thought that the corresponding initial error is highly positively correlated with this EOF mode. For these summer PB-related initial errors, we, according to the signs of the PCs of the corresponding EOF modes, classify them into six groups and denote them as G-EOF1+, G-EOF1-, G-EOF2+, G-EOF2-, G-EOF3+, and G-EOF3-.

For each of the predetermined models, we repeat the above steps and take the composite of the summer PB-related initial errors in each group, finally obtaining 36 composite initial errors. By observing the patterns of these 36 initial errors, it is found that two composite initial errors arise in all six models. This indicates that these two composite initial errors can cause summer PB for CP-El Niño events in all six models, and if they are filtered from corresponding initial analysis from control forecasts, a significant improvement in forecast skill can be found in the CP-El Niño predictions made by the six models. Exactly, these two initial errors are represented by the composite patterns of the summer PBrelated initial errors in the G-EOF1+ and G-EOF2- groups. To facilitate the description, we denote these two composite initial errors as CP-type-1 and CP-type-2 errors, which include the ocean temperature and horizontal wind components and are illustrated in Figs. 5 and 6, respectively. The CP-type- 1 error presents an SST chain structure of negative-positive-negative-positive anomalies along the region from the northwestern Pacific and then the eastern tropical Pacific to the southeastern Pacific and a subsurface temperature dipolar structure of positive anomalies in the central-eastern equatorial Pacific and negative anomalies in the lower layers of the western equatorial Pacific. Furthermore, for all the selected models, the negative anomalies of the CP-type- 1 errors in the equatorial Pacific are mainly located at $90-155 \mathrm{~m}$, and positive anomalies are above $60 \mathrm{~m}$; the CP-type-1 errors over the northern Pacific exhibit strong anomalies above $55 \mathrm{~m}$, with negative anomalies near the northwest of Midway Island and positive anomalies along the Gulf of Alaska. This North Pacific error pattern shows great resemblance to the Victoria Mode (VM) suggested by Bond et al. (2003) (also see Ding et al. 2015b). Over the southeastern Pacific, the CP-type-1 errors exhibit negative anomalies mainly in the upper layers, showing a general 
(a)CCSM4

(b)CESM1-BGC

(c)CMCC-CMS

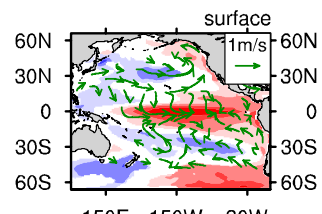

$150 \mathrm{E} 150 \mathrm{~W}$ 90W

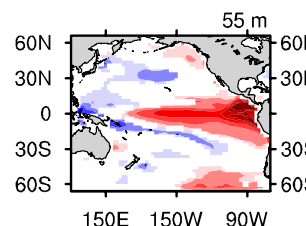

$150 \mathrm{E}$ 150W 90W
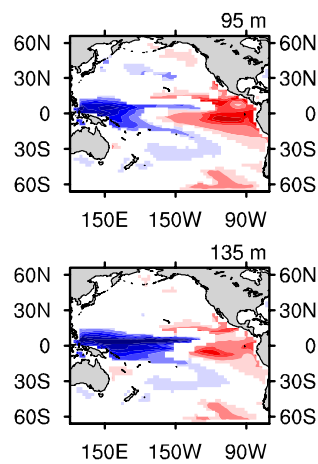

vertical profile
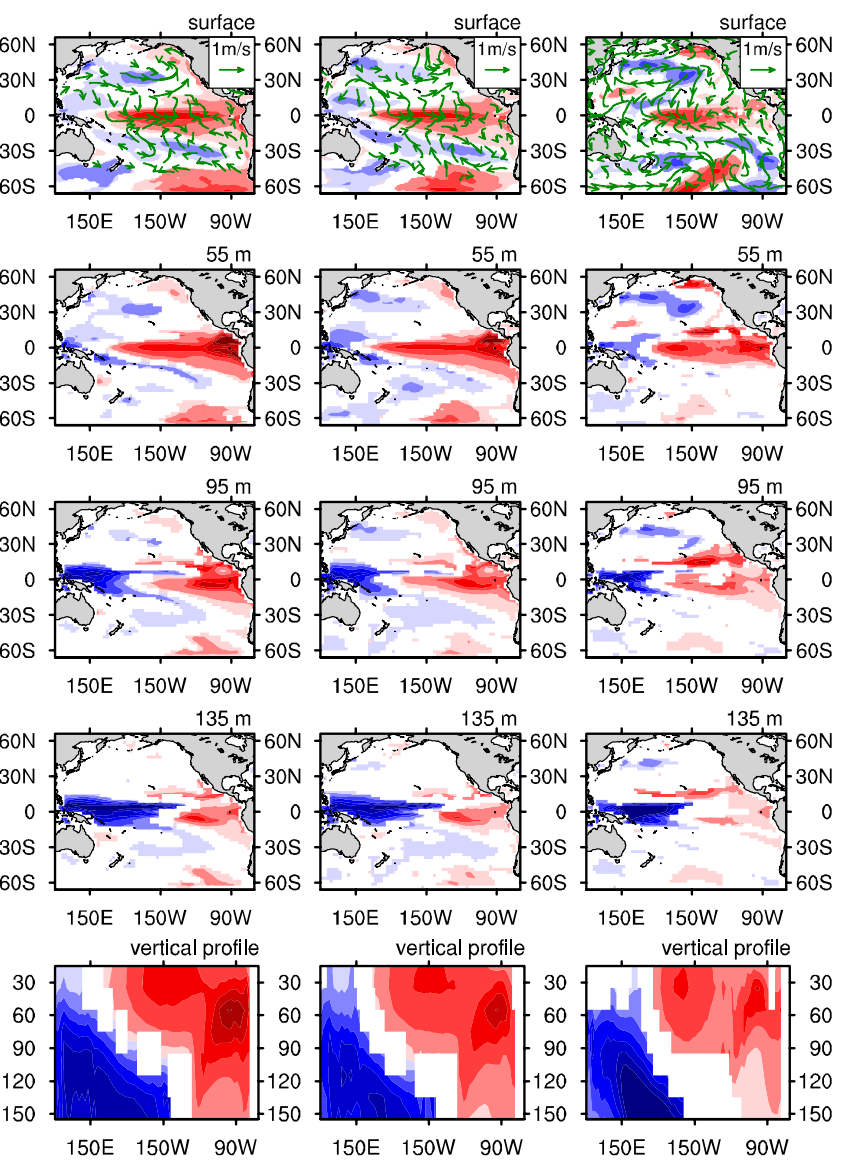

$150 \mathrm{E}$ 150W $90 \mathrm{~W}$

$150 \mathrm{E} 150 \mathrm{~W}$ 90W

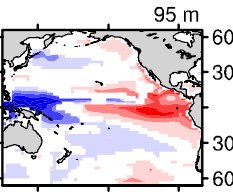

$150 \mathrm{E}$ 150W 90W

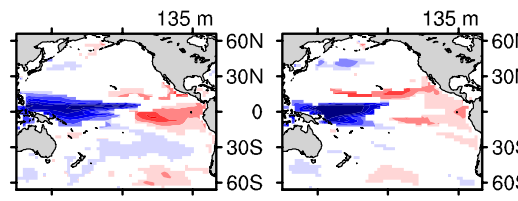

$150 \mathrm{E}$ 150W 90W

vertical profile

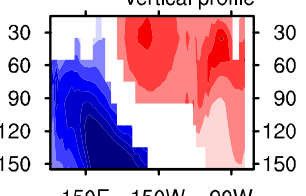

$150 \mathrm{E}$ 150W 90W

(d)CNRM-CM5

(e)GFDL-CM3

(f)GISS-E2-R

Fig. 5 Composite of anomalous sea temperature (units: ${ }^{\circ} \mathrm{C}$ ) and horizontal wind (units: $\mathrm{m} / \mathrm{s}$ ) components of the CP-type-1 errors derived by the pi-Control run of a CCSM4, b CESM1-BGC, $\mathbf{c}$ CMCC-CMS, d CNRM-CM5, e GFDL-CM3, and f GISS-E2-R. The top 4 rows

resemblance to the South Pacific Meridional Mode (SPMM) (Zhang et al. 2014; Min et al. 2017). As shown in Fig. 6, the CP-type-2 initial errors exhibit strong anomalies only over the North Pacific, with a pattern of negative anomalies near the Alaska region, positive anomalies over the central-north Pacific and negative anomalies over the subtropics near Baja California. Clearly, such a pattern is almost opposite to the northern Pacific component of CP-type-1 initial errors (i.e., the Victoria Mode). The CP-type- 1 and -2 errors imply that the predictions of CP-El Niño events are sensitive to not only the initial errors occurring over the tropical Pacific but also to those over the north and south Pacific, and the interaction among them causes the occurrence of summer PB. Therefore, how do these two types of initial error patterns evolve and influence the prediction of CP-El Niño?

By tracing the evolution of the summer PB-related initial errors in the six models, we found that for CP-type-1 initial errors, their evolutionary behaviors are similar to a La Niña-like evolving mode and trigger a cold bias of

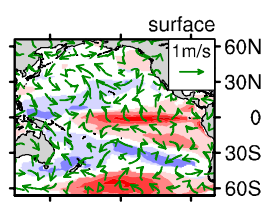

$150 \mathrm{E} 150 \mathrm{~W} 90 \mathrm{~W}$
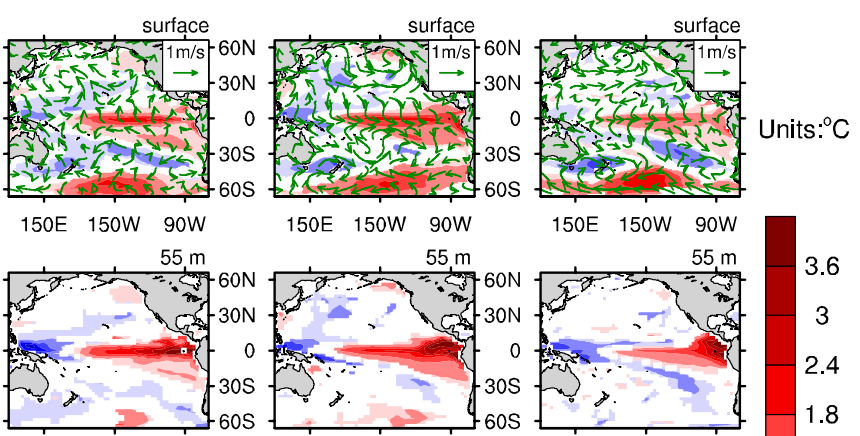

$150 \mathrm{E} 150 \mathrm{~W}$ 90W

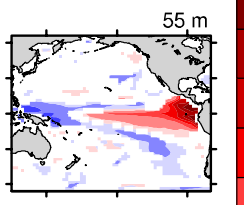

3.6

3

2.4

$150 \mathrm{E}$ 150W 90W

$150 \mathrm{E}$ 150W 90W

$150 \mathrm{E} 150 \mathrm{~W}$ 90W 1.2

$95 \mathrm{~m}$
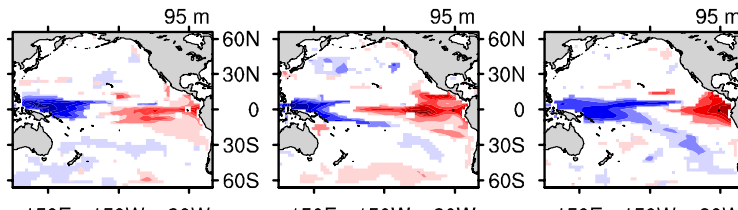

$5 \mathrm{~m}$

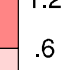

.6

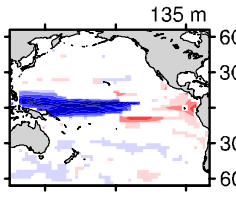

$150 \mathrm{E}$ 150W 90W

vertical profile

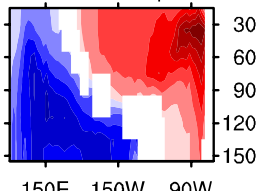

$150 \mathrm{E}$ 150W $90 \mathrm{~W}$

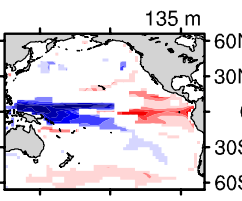

$150 \mathrm{E}$ 150W $90 \mathrm{~W}$
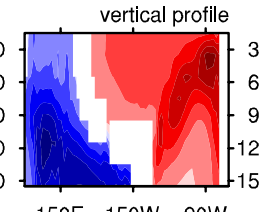

$150 \mathrm{E}$ 150W 90W

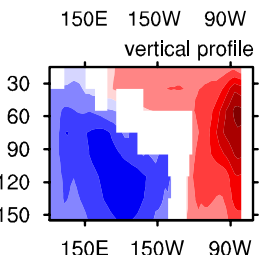

correspond to ocean depths from the sea surface of $0 \mathrm{~m}, 55 \mathrm{~m}, 95 \mathrm{~m}$ and $135 \mathrm{~m}$. The bottom row is the meridional mean of the sea temperature anomaly over $5^{\circ} \mathrm{S}-5^{\circ} \mathrm{N}$. Composites of initial errors not exceeding the $95 \%$ significance level are masked

predictions in the central-eastern equatorial Pacific in December (Fig. 7e). In other words, the CP-type-1 initial errors have a tendency to cause underpredictions for the CP-El Niño events in terms of amplitude. All six models share similar evolutionary behaviors of prediction errors caused by CP-type-1 errors. For simplicity, we only show in Fig. 7 the evolution of the summer PB-related initial errors in the CCSM4 model. It is shown that the CP-type-1 initial errors tend to first experience a decaying period of El Niño and then undergo a transition to a typical La Niña-like evolving mode, where the transition occurs during the period of April-May-June. From a physical perspective, the positive errors of SST over the central-eastern equatorial Pacific in CP-type-1 errors boost strong westward winds over the central equatorial Pacific, which generates westward-propagating Rossby waves. Once the Rossby waves reach the western ocean boundary, upwelling Kelvin waves that travel eastwards could be induced. These Kelvin waves gradually deliver 
(a)CCSM4
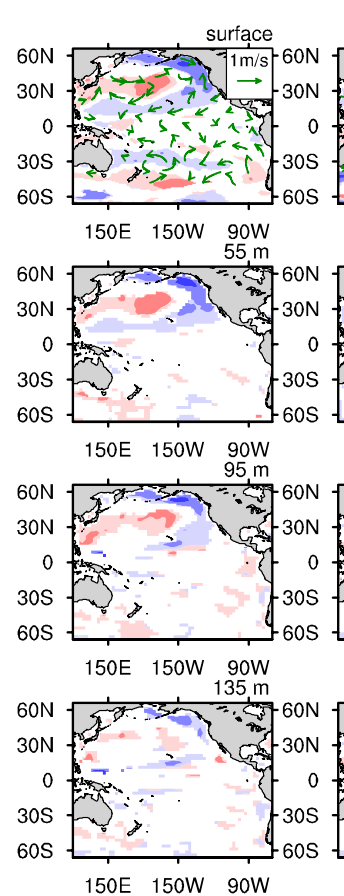

150E 150W 90W
(b)CESM1-BGC

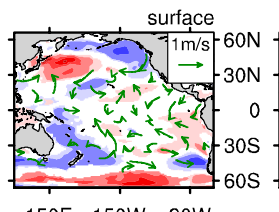

150E 150W 90W

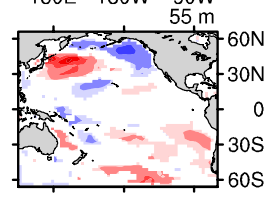

150E 150W 90W

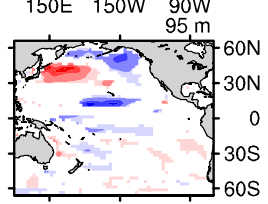

150E 150W 90W

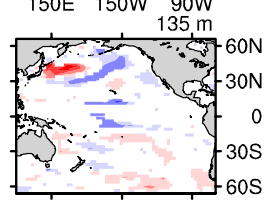

150E 150W 90W
(c)CMCC-CMS
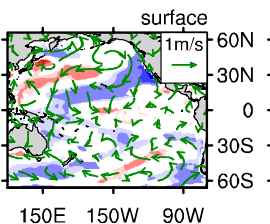

150E $150 \mathrm{~W} 90 \mathrm{~W}$

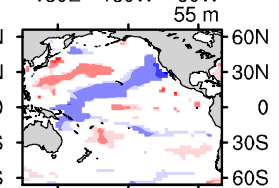

150E 150W 90W

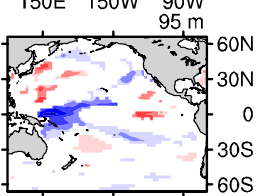

150E 150W 90W

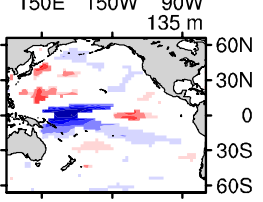

150E 150W 90W
(d)CNRM-CM5
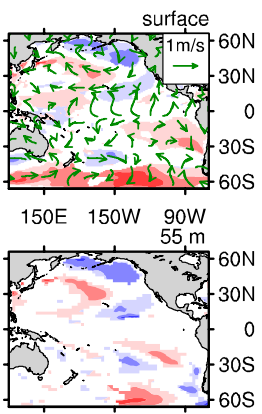

150E $150 \mathrm{~W}$.

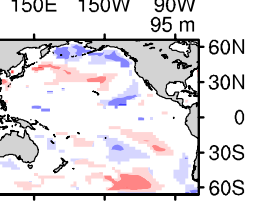

150E 150W 90W

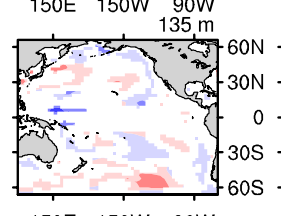

150E 150W 90W
(e)GFDL-CM3

(f)GISS-E2-R

Fig. 6 As in Fig. 5, but for CP-type-2 error

the strong lower-level negative anomalies in the equatorial western Pacific to be upwards and eastwards, which offset the upper-level positive SST anomalies over the centraleastern Pacific. Once the positive SST errors disappear and the negative SST errors appear over the eastern equatorial Pacific, eastward wind anomalies will be generated, which will amplify the cooling process due to the Bjerknes positive feedback mechanism (Bjerknes 1968) and gradually yield a cold bias in December. In addition, it is noticeable that extratropical components of the CP-type-1 errors also have significant effect on the prediction errors of the CP-El Niño events. They especially influence the deep tropics via wind-evaporation-SST (WES) feedback (Xie and Philander 1994). Specifically, over the south Pacific, the negative SPMM-like SST mode is accompanied by cyclonic wind anomalies and can transport the negative error into the equatorial Pacific, finally accelerating the disappearance process of the positive SST anomalies over the central-eastern equatorial Pacific from January to March, which enhances the cold bias of the SST over the eastern equatorial Pacific. However, the evolutionary process of the CP-type-1 errors over the northern Pacific (i.e., the VM-like SST error) opposes the formation of the negative error over the central-eastern equatorial Pacific. At first, the positive SST anomalies along the Alaska Gulf feed back onto and modify near surface horizontal winds via convection. The wind anomalies generated by the convection tend to transport the positive anomalies southward to the equator, which suppresses the formation of the negative anomalies over the central-eastern equatorial Pacific. Therefore, this process fights against the two previously mentioned processes associated with the equatorial and south Pacific. However, the equatorial oceanic process and the southern Pacific evolutionary process win and generate large negative prediction errors in the equatorial centraleastern Pacific in December.

As for CP-type-2 initial errors, all six models also present similar dynamical behaviors. Here, we also take the CCSM4 as an example to describe the results (see Fig. 8). It is shown that the evolution of CP-type-2 error is similar to a La Niña evolving mode but from a neutral mode, triggering a cold bias of prediction, especially in the Niño4 area in December. Physically, it is opposite to the evolutionary process of the VM-like component of the CP-type-1 initial errors. The negative SST anomalies off Baja California, along with the wind anomalies, generated by the convection, help new negative anomalies form in the south. Then, the atmosphere continuously responds to the new SST anomalies through producing wind anomalies farther southwestwards. Once the negative anomalies arise over the equatorial Pacific in March, the Bjerknes positive feedback mechanism is triggered, which helps the negative anomalies enlarge and propagate westwards to the central Pacific. In December, the negative anomalies are stronger in the Niño4 area, which causes underpredictions of the CP-El Niño events in terms of amplitude. 

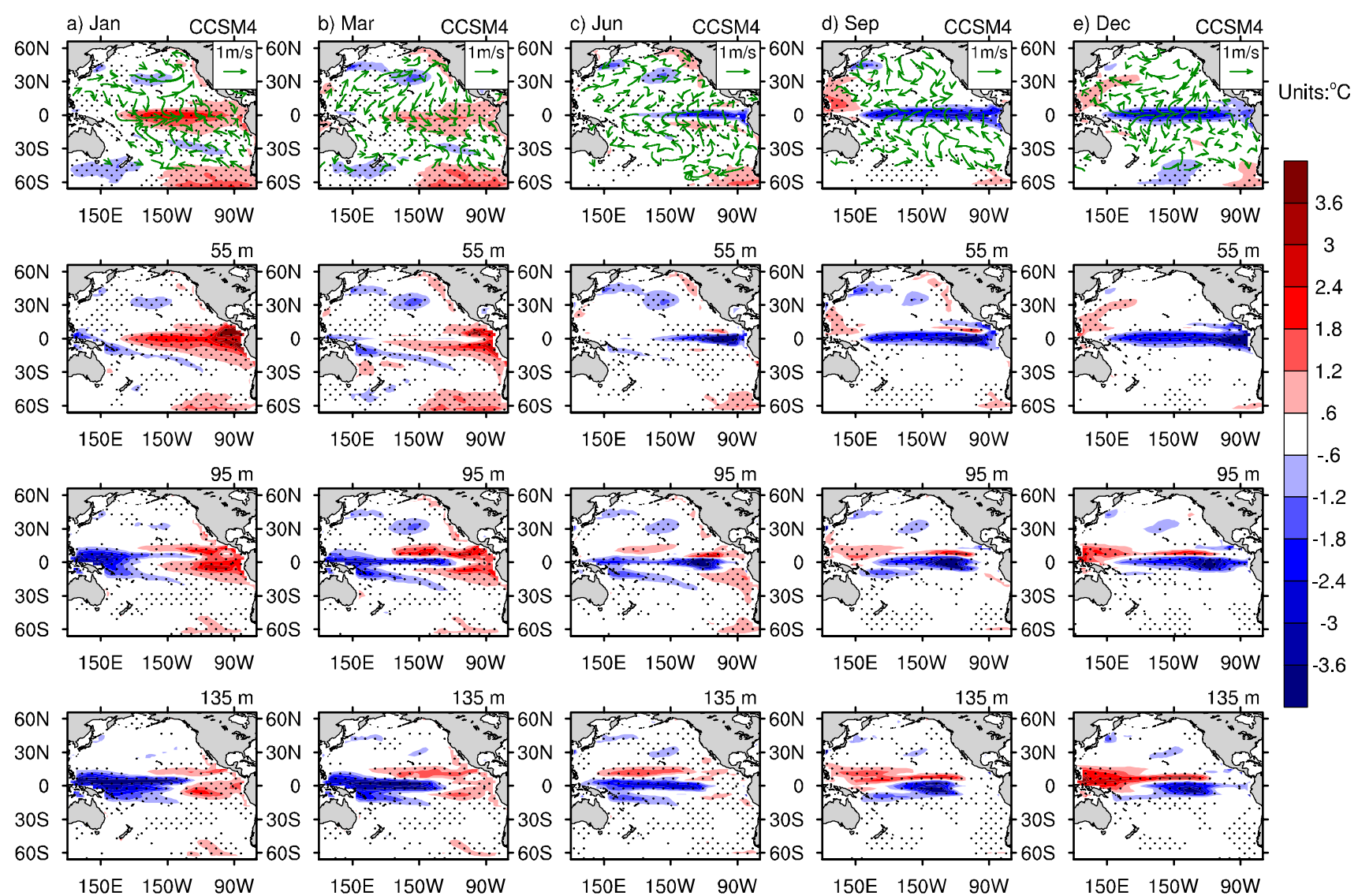

Fig. 7 Composite of the evolutions of anomalous sea temperature (units: ${ }^{\circ} \mathrm{C}$ ) and horizontal wind (units: $\mathrm{m} / \mathrm{s}$ ) of CP-type-1 errors as shown in a January, b March, c June, d September, and e December. The dotted areas denote those exceeding the $95 \%$ significance

level. The rows correspond to sea depths from the sea surface of $15 \mathrm{~m}, 55 \mathrm{~m}, 95 \mathrm{~m}$ and $135 \mathrm{~m}$. This figure is plotted according to the CCSM4 model

\section{The spring PB for EP EI Niño and its related initial error growth}

In this section, we focus on the PB for EP-El Niño events. Quite a few studies have explored the PB of EP-El Niño events and illustrated the spring PB for EP-El Niño events (Webster and Yang 1992; Duan and Wei 2012; Qi et al. 2017), implying that the prediction errors tend to grow significantly during spring (Duan and $\mathrm{Hu} 2015$ ). In Sect. 3, we found that the SSTA associated with EP-El Niño can lead to a spring persistence barrier, showing unstable growth of the SSTA associated with EP-El Niño in spring. It is therefore understandable that the spring unstable growth dynamics of the signal EP-El Niño contributes to the growth of its prediction errors in spring and causes the occurrence of the spring PB for EP-El Niño. In addition, numerous studies emphasized the role of initial uncertainties occurring in the tropical Pacific Ocean in yielding spring PB for EP-El Niño (Moore and Kleeman 1996; Chen et al. 2004; Duan et al. 2009; Yu et al. 2009; Tian and Duan 2015). However, as mentioned in the introduction, recent studies have shown

that the extratropical sea temperature variability also influences the tropical El Niño. Therefore, in the present study, we are interested in how the uncertainties occurring in the extratropical Pacific interact with those in the tropical Pacific and influence the spring PB for EP-El Niño events and what structure features the initial errors that occur in extratropical and tropical Pacific sea temperature and have large tendency to cause spring PB for EP El Niño events.

To be consistent with the approach used in exploring CP-El Niño events, we also select 13 typical EP-El Niño events and make 40 predictions for each of the El Niño events by using the approach described in Sect. 2; 520 predictions are then obtained in total for 13 EP-El Niño events. Figure 9 presents the ensemble mean of the monthly growth rates of the Niño3 SSTA component of the prediction errors for the 520 predictions of each model. It is shown that the prediction errors of the Niño3 SSTA grow significantly from May to June and result in spring PBs despite some models also presenting significant error growth in winter. Figure 10 shows the evolutionary behaviors of prediction errors for different EP-El Niño events. Comparing Figs. 3 and 4 for 


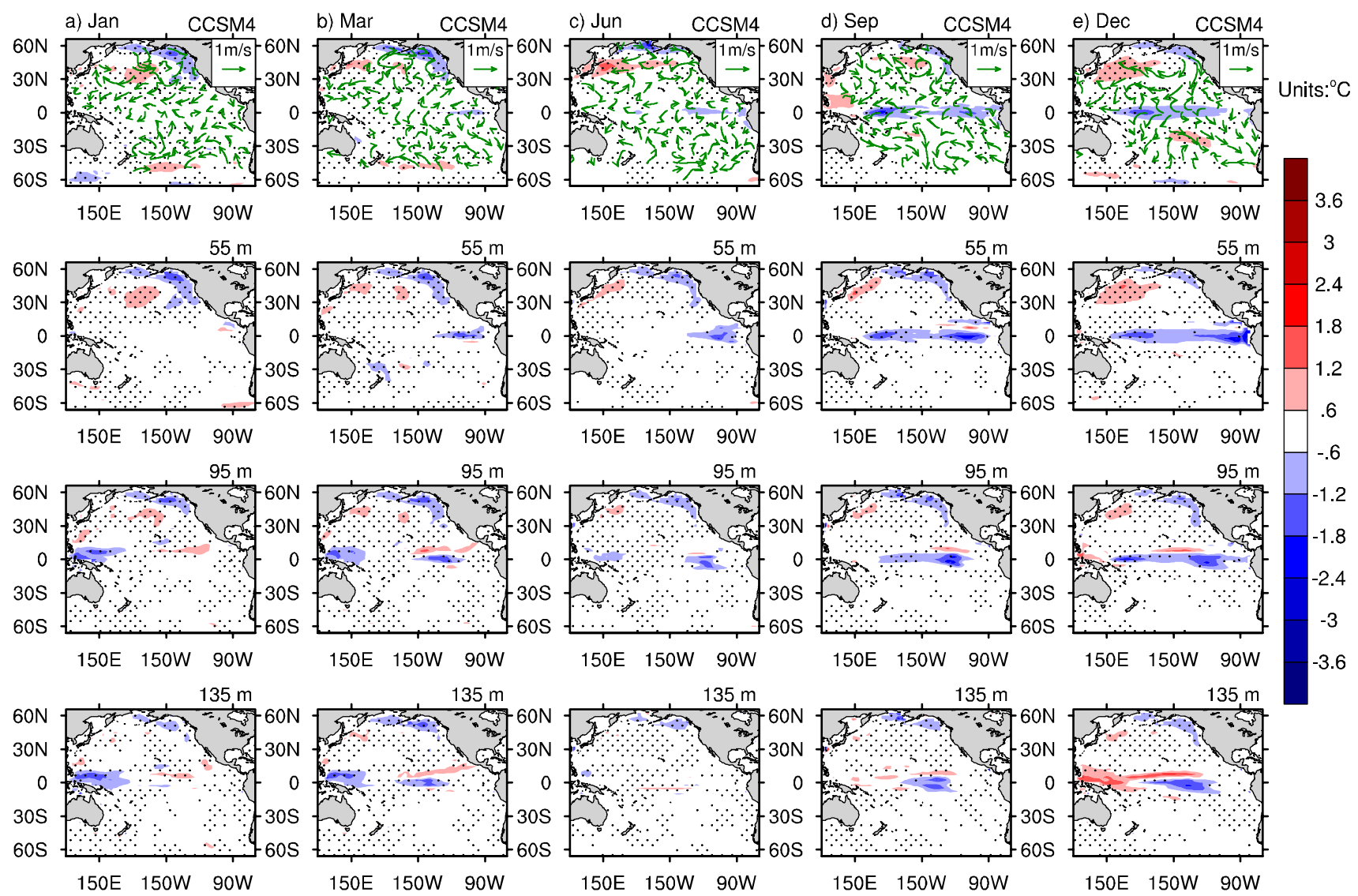

Fig. 8 As in Fig. 7, but for the CP-type-2 error

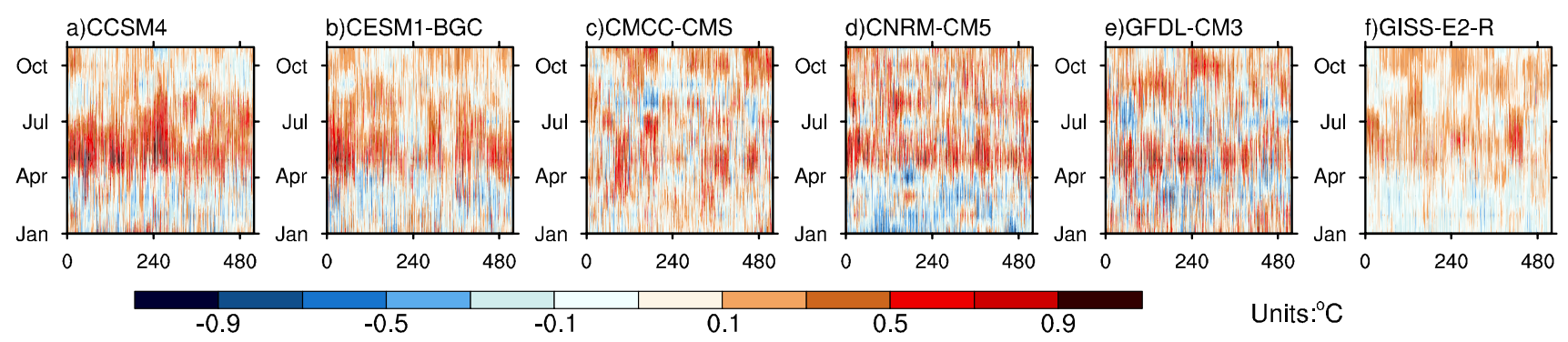

Fig. 9 As in Fig. 3, but for EP-El Niño

CP-El Niño with Figs. 9 and 10 for EP-El Niño, it is found that the positive error growth rate for EP-El Niño is often larger than that of the CP-El Niño events, and the prediction error at the final time of the 12-month lead prediction is also much larger. It is obvious that the spring PB for EP-El Niño events is stronger than the summer PB for CP-El Niño.

To explore in particular initial errors that can cause significant spring PB for EP El Niño events, all the predictions that have spring PB (hereafter "spring PB-related predictions") in all the predetermined models are selected. The numbers of the spring PB-related predictions in each model are given in Fig. 10. Then, an EOF analysis is applied to their initial errors over the Pacific region $\left[66.5^{\circ} \mathrm{S}-66.5^{\circ} \mathrm{N}, 120^{\circ} \mathrm{E}-70^{\circ} \mathrm{W}\right]$. Similar to the CP El Niño, the first three EOF modes (which explained approximately $35 \%$ of the total variances of the initial errors for each model) are of concern. For each of the selected six models, the spring PB-related initial errors are similarly based on the corresponding PCs of the EOF mode and classified into six groups: G-EOF1+, G-EOF1-, G-EOF2+, G-EOF2-, G-EOF3+, and G-EOF3-. In the present study, we aim at finding a comprehensive initial error mode that 
Fig. 10 As in Fig. 4, but for EP-El Niño
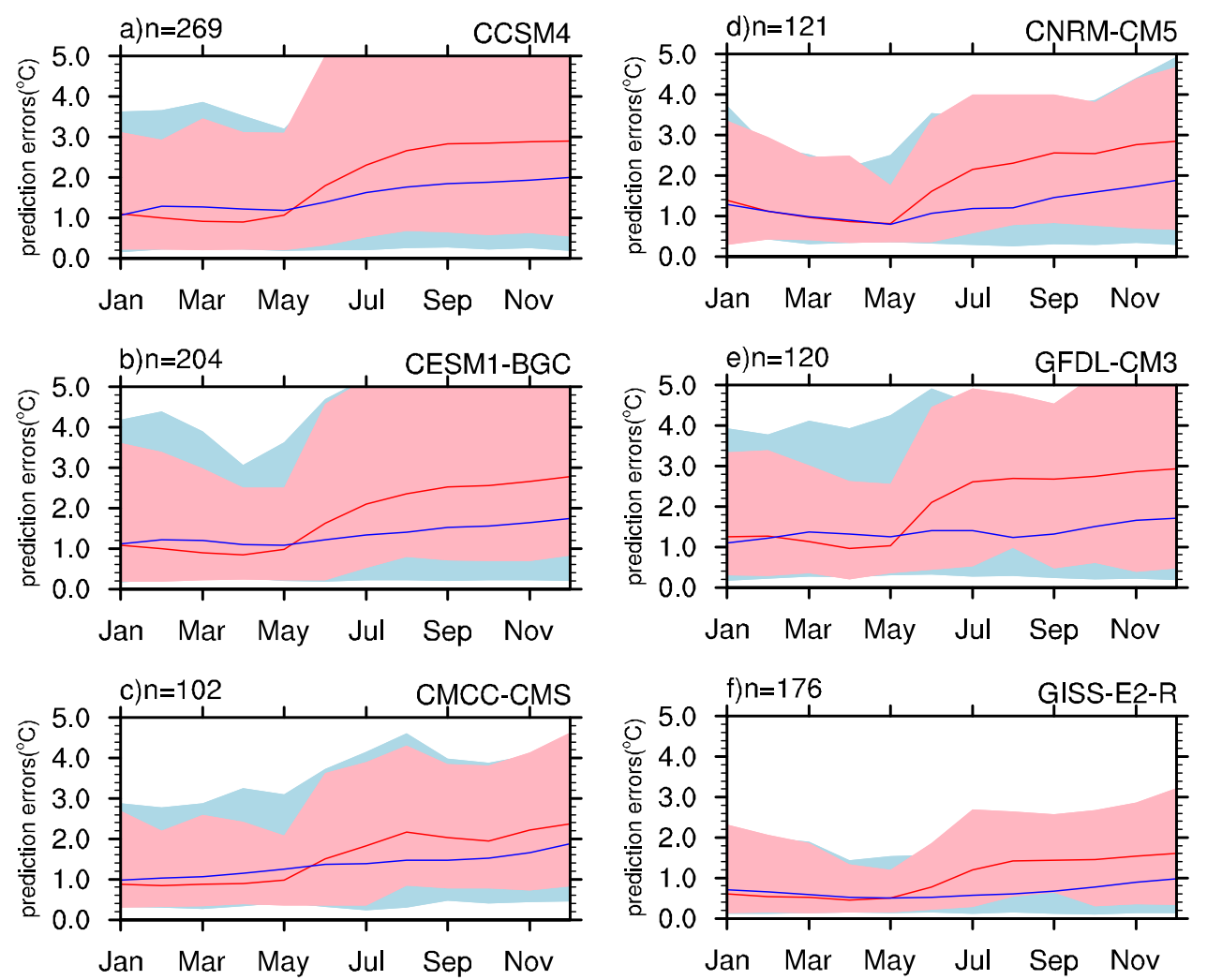

can cause spring PB for EP El Niño events and use the results to provide useful information for improving ENSO forecast skill. As such, we select the groups whose initial errors show similar structure for most of the predetermined six models so that the resultant spring PB-related initial errors can be less model-dependent. Consequently, the spring PB-related initial errors in the groups denoted by G-EOF1+ and G-EOF1- are selected. Specifically, CCSM4, CESM-BGC, CMCC-CMS and GFDL-CM3 present the structure of spring PB-related initial errors in the group of G-EOF1+, whereas the CCSM4, CESM-BGC, CMCC-CMS and GISS-E2-R exhibit the pattern of the spring PB-related initial errors in the group of G-EOF1-. We take the corresponding composites of these two groups of initial errors (see Figs. 11, 12) and denote them as EPtype-1 and - 2 initial errors. It is shown that the EP-type-1 initial errors have a pattern similar to the CP-type-1 initial errors. That is, there exists an SST chain structure of negative-positive-negative-positive anomalies along the region from the northwestern Pacific and then the eastern tropical Pacific to the southeastern Pacific and a subsurface temperature dipolar structure of positive errors in the central-eastern equatorial Pacific and negative errors in the lower levels of the western equatorial Pacific; along with the vertical profile, they present negative errors of the sea temperature in the region of $120^{\circ} \mathrm{E}-150^{\circ} \mathrm{W}, 5^{\circ} \mathrm{S}-5^{\circ} \mathrm{N}$, 90-155 m. For the EP-type-2 initial error, we can see from
Fig. 12 that it possesses similar structure to the EP-type-1 initial error but is of almost opposite signs.

To further illustrate the evolutionary behavior of these EP-type-1 and -2 errors, we consider the anomaly sea temperature and wind components of the prediction errors caused by the two types of initial errors. Because relevant models possess similar evolutionary behaviors of the two types of errors, we only take the CCSM4 as an example to show the results (see Figs. 13 and 14). As shown above, the EP-type-1 initial error bears great similarities to the CPtype-1 initial error. However, the EP-type-1 error is superimposed on the EP-El Niño events, whereas the CP-type-1 error is imposed on the CP-El Niño events. Despite this, the EP-type-1 error still presents similar evolutionary behaviors to that of the CP-type-1 error. That is, the EP-type-1 initial error evolves similar to a La Niña event and triggers a cold bias of prediction in the central-eastern equatorial Pacific in December (Fig. 13e). Specifically, the positive errors of the SST over the central-eastern equatorial Pacific in EP-type-1 error boost strong westward winds over the central equatorial Pacific, generating Rossby waves that propagate westwards. As soon as the Rossby waves reach the western ocean boundary, they induce upwelling Kelvin waves that propagate eastwards. These Kelvin waves gradually carry the negative anomalies in the lower-level western equatorial Pacific upwards and eastwards to the sea surface, which offset the positive SST anomalies over the upper-level central-eastern 
(a)CCSM4

(b)CESM1-BGC

(c)CMCC-CMS
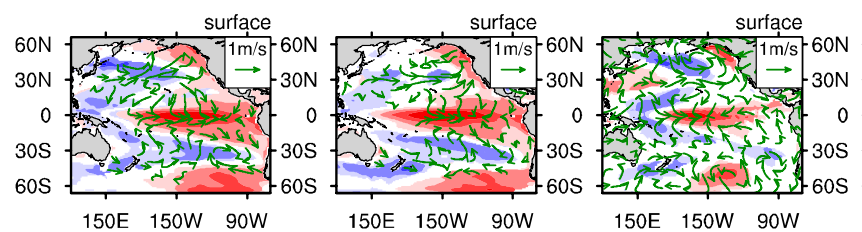

(d)CNRM-CM5

(e)GFDL-CM3

(f)GISS-E2-R
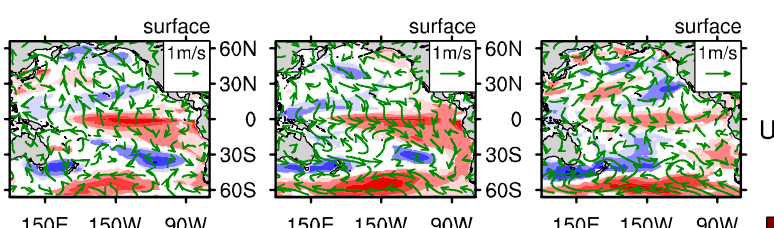

150E $150 \mathrm{~W}$ 90W
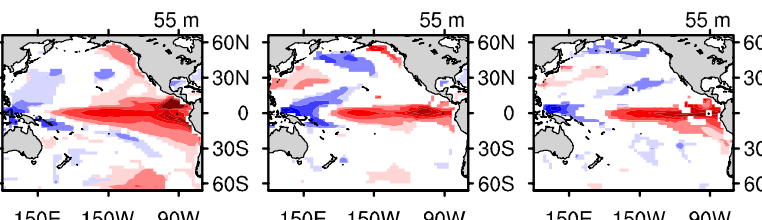

150E 150W 90W
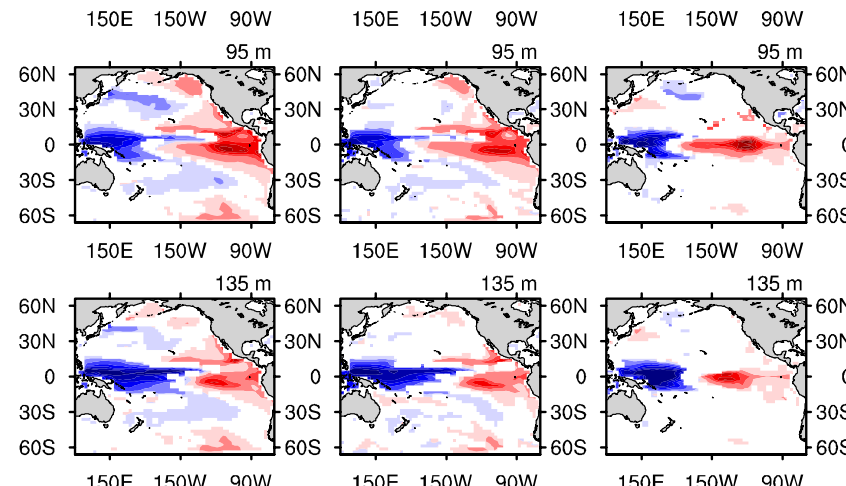

150E 150W 90W vertical profile

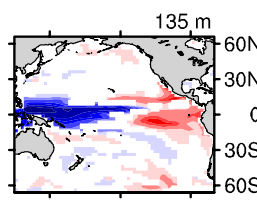

150E 150W 90W
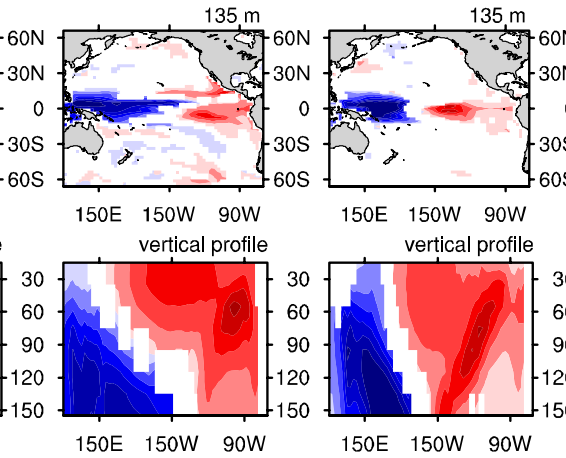

150E 150W 90W

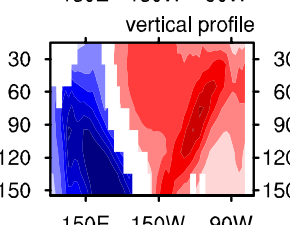

150E 150W 90W
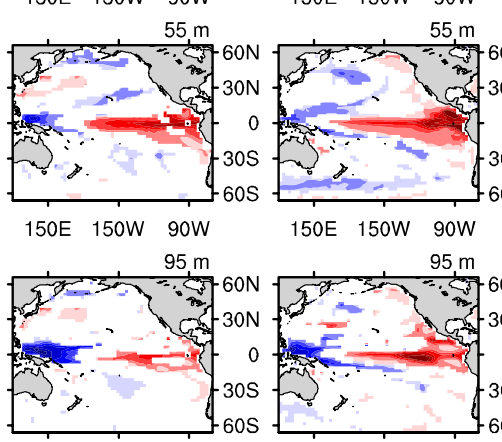

$150 \mathrm{E}$ 150W 90W

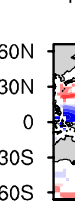

150E 150W 90W

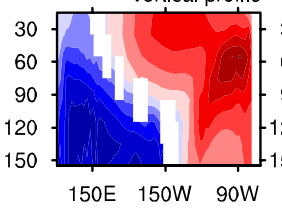

$150 \mathrm{E}$ 150W 90W
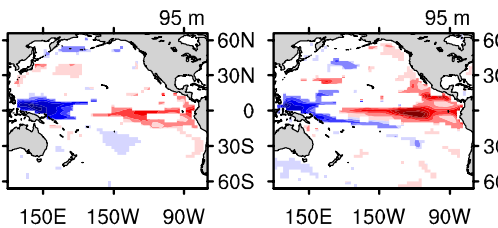

$150 \mathrm{E} \quad 150 \mathrm{~W}$ 90W

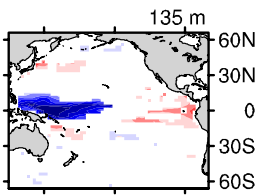

150E 150W 90W

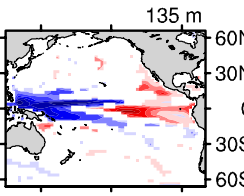

150E 150W 90W
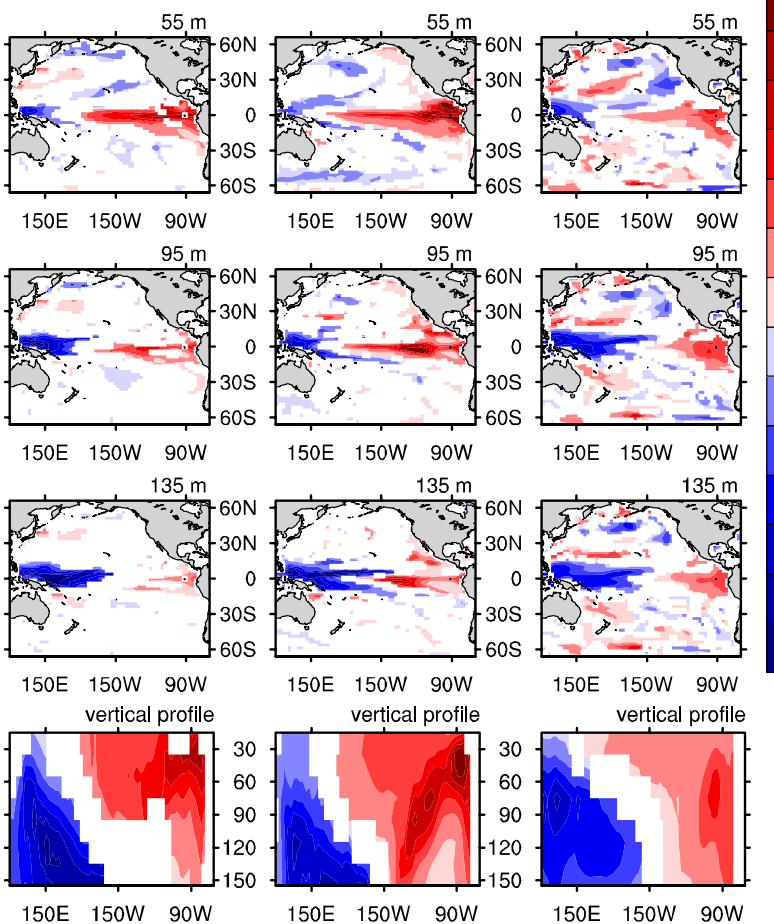
Units: ${ }^{\circ} \mathrm{C}$

3.6

Fig. 11 As in Fig. 5, but for the EP-type-1 error for EP-El Niño

Pacific. The positive SST errors fade away, and the negative SST errors appear over the upper-level eastern Pacific during March to June (see Fig. 13b, c). Then, the Bjerknes positive feedback mechanism is formed and helps the negative SST errors extend westwards and thus yield a large cold bias over the upper-level central-eastern Pacific in December. Meanwhile, the southeastern Pacific SPMM-like negative error component in the EP-type-1 errors also transports negative errors into the equator via the WES mechanism and helps the negative errors over the upper-level eastern equator emerge and extend westward from January to June. However, the North Pacific VM-like positive error component opposes the above positive mechanism and is defeated. Consequently, the negative SST errors in the eastern equatorial Pacific are very strong and cause an underprediction for EP-El Niño.

As for EP-type-2 initial errors, their evolution also bears great resemblance to an evolution of La Niña, but from a weak La Niña-like phase, which finally generates negative errors of SST anomalies over the central-eastern equatorial Pacific. Physically, the negative errors over the central-eastern Pacific trigger the east wind anomalies, and, thus, the Bjerknes positive feedback mechanism forms, bringing more negative anomalies from the lower level and strengthening the negative SST anomalies in the central-eastern Pacific. In addition, the negative errors in the northeastern Pacific induce the wind anomalies that will influence the tropics and enlarge the negative equatorial anomalies through the WES mechanism. However, the weakly positive errors over the southeastern Pacific oppose the strengthening of the negative errors over the central-eastern equatorial Pacific. In addition, the shallow positive anomalies in the lower-level western equatorial Pacific would also undermine the negative anomalies in the upper-level central-eastern Pacific through the activated upwell Kelvin waves. These two processes fight against the two positive feedback mechanisms but are defeated. Therefore, the negative SST anomalies in the eastern equatorial Pacific are presented in December and cause an underprediction for EP-El Niño events. 
(a)CCSM4

(b)CESM1-BGC

(c)CMCC-CMS
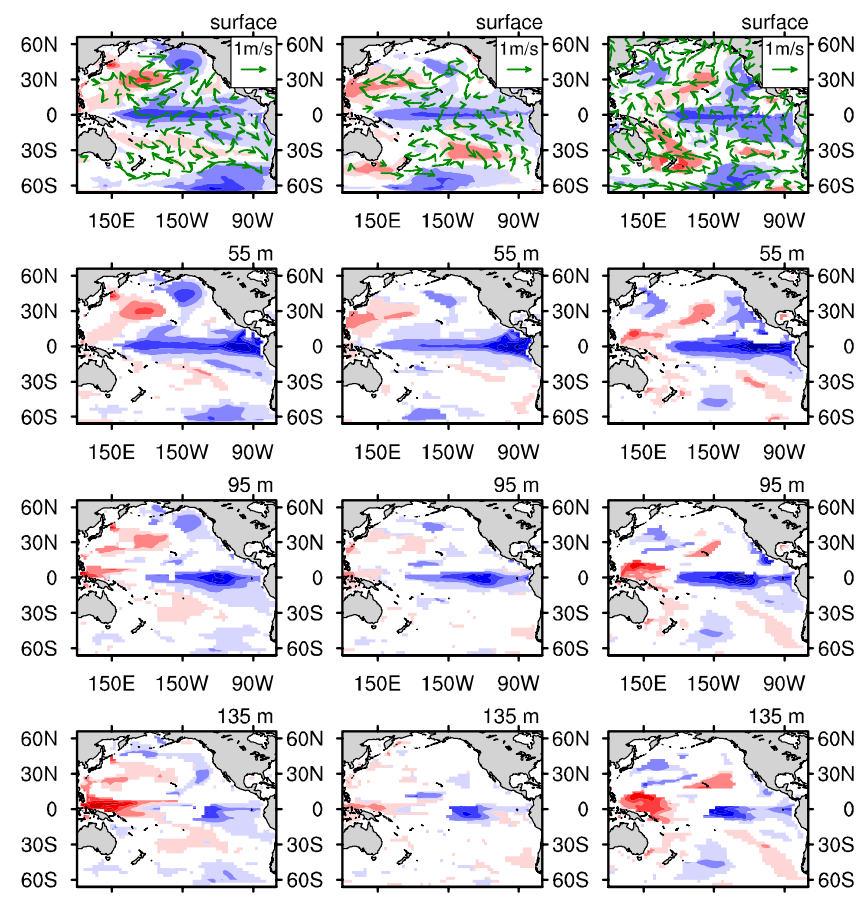

150E 150W 90W
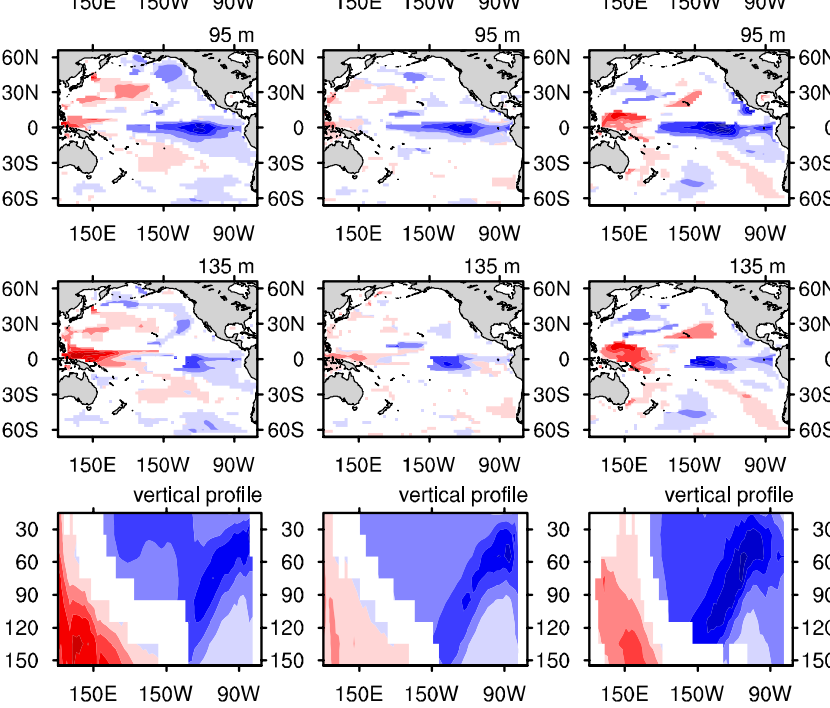

(d)CNRM-CM5

(e)GFDL-CM3

(f)GISS-E2-R
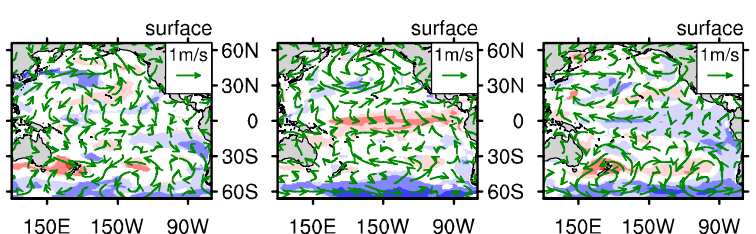

$150 \mathrm{E} 150 \mathrm{~W}$ 90W

$150 \mathrm{E} 150 \mathrm{~W}$ 90W

$150 \mathrm{E} 150 \mathrm{~W} 90 \mathrm{~W}$

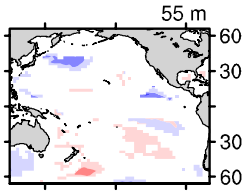

$150 \mathrm{E}$ 150W 90W

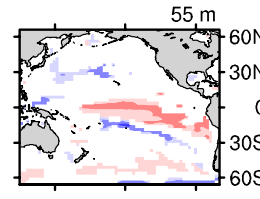

$95 \mathrm{~m}$

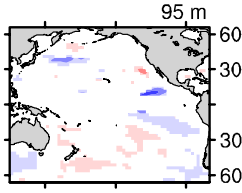

$150 \mathrm{E}$ 150W $90 \mathrm{~W}$

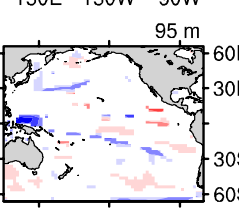

$150 \mathrm{E} 150 \mathrm{~W} 90 \mathrm{~W}$

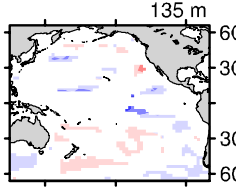

$150 \mathrm{E}$ 150W 90W vertical profile
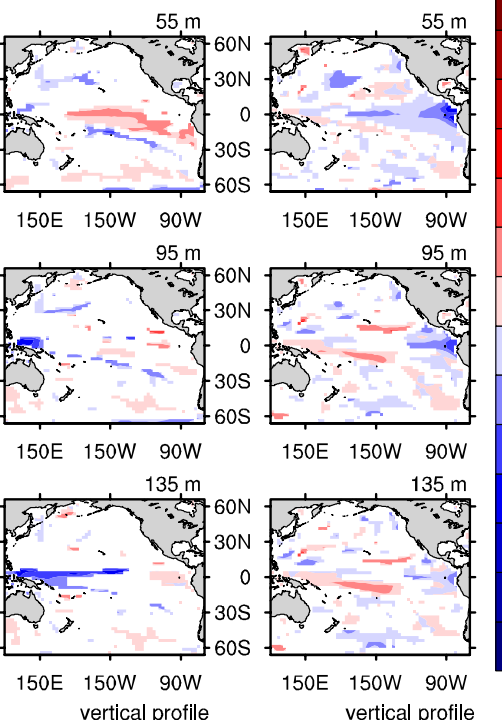

3.6

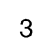

2.4

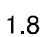

1.2
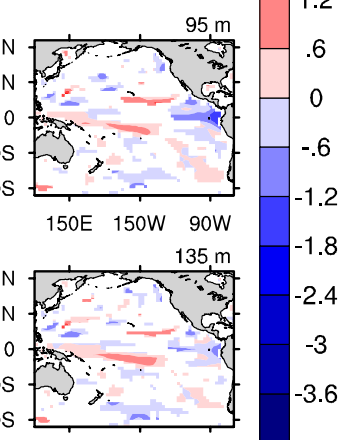

150E 150W 90W vertical profile
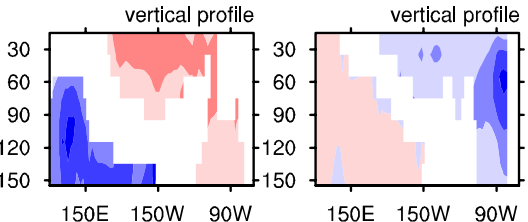

Fig. 12 As in Fig. 6, but for the EP-type-2 error for EP-El Niño

\section{Why do the PB-related initial errors for El Niño develop similar to a La Niña evolving mode?}

In Sects. 4 and 5, we discovered that both the summer PBrelated initial errors for CP-El Niño and the spring PB-related initial errors for EP-El Niño events evolve like a La Niña evolving mode, i.e., presenting an opposite phase of the concerned El Niño events, and eventually result in a negative anomaly of the SST over equatorial Pacific in December. In this section, we declare why the PB-related initial errors for El Niño tend to develop into a La Niña-like cooling mode.

The variable $T$ is used to denote the El Niño-related monthly SST and $P_{i}$ are its 40 predictions, where $i=1,2, \ldots, 40$. The composite of the 40 prediction errors can be derived as follows in Eq. (11):

$$
E=\frac{1}{40} \sum_{i=1}^{40}\left(P_{i}-T\right)=\frac{1}{40} \sum_{i=1}^{40} P_{i}-T .
$$

Herein, the "observed" El Niño-related SST (i.e. T) is picked from the 500-year integration of the model and its 40 predictions $P_{i}$ are obtained by taking 401 -year periods of SST round it. Thus the first term on the right side of Eq. (11) implies the climatology of SST in the model due to the methodology we utilized. The Eq. (11) can be rewritten as follows:

$E \approx \bar{T}-T=-(T-\bar{T})=-T_{a}$,

where $\bar{T}$ represents the climatology of SST, and $T_{a}$ represents the anomalies of "observed" El Niño-related SST ( $T$ ). From Eq. (12), we infer that the composite of 40 prediction errors for each El Niño event tend to evolve in the way opposite to an El Niño evolution and like a La Niña-like evolution. The PB-related initial errors we showed in Sects. 4 and 5 are extracted from these 40 initial errors, which can induce $\mathrm{PB}$ phenomenon and yield large prediction errors. And when the prediction errors caused by the 40 initial errors are taken as ensemble members to perform a composite $E$, it mainly reflects much stronger prediction errors caused by the PBrelated initial errors. Therefore, the Eq. (11) sheds light on 

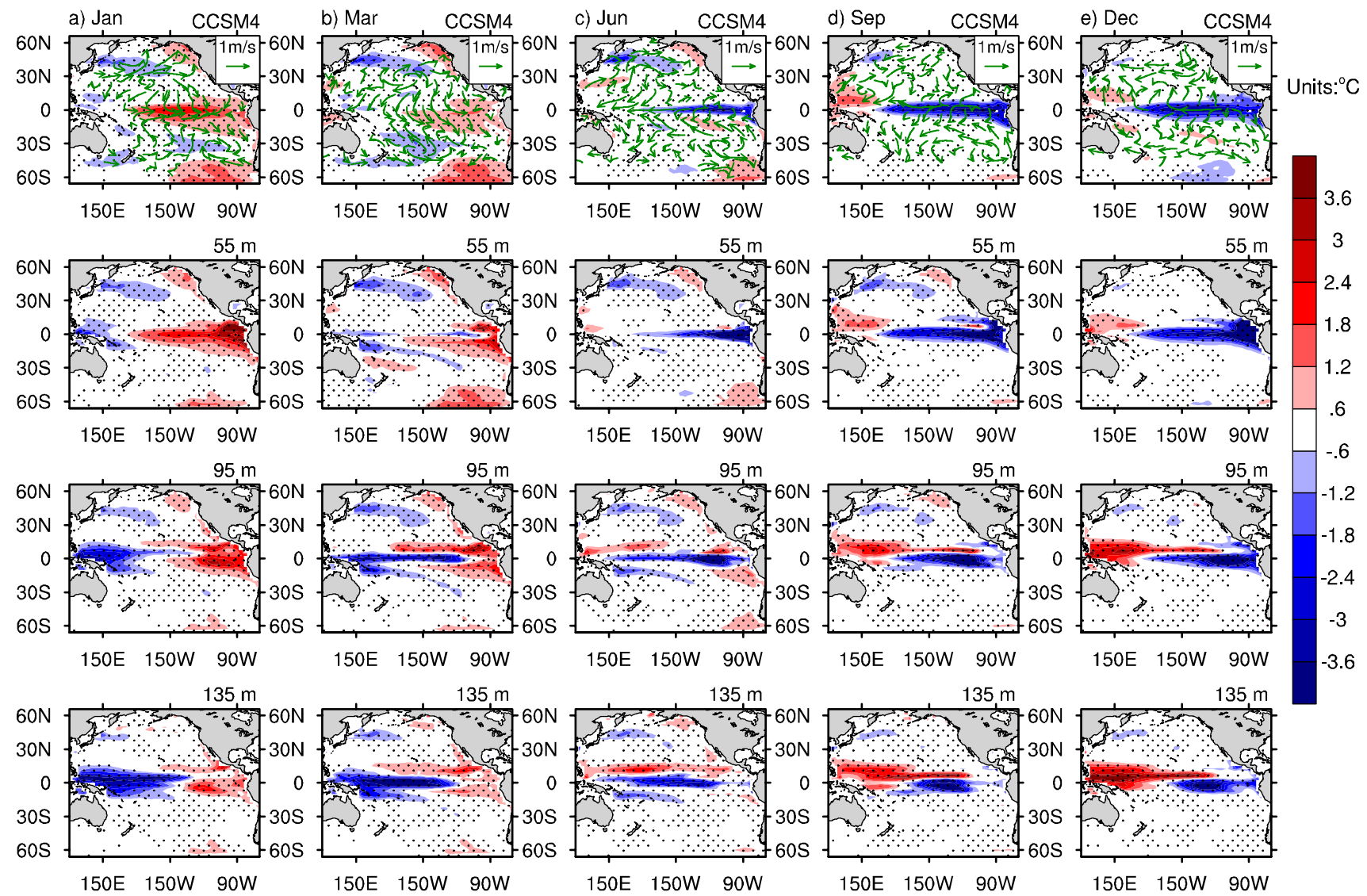

Fig. 13 As in Fig. 7, but for the EP-type-1 error for EP-El Niño

the composite of the PB-related initial errors behaving similar to a La Niña-like evolving mode. That is, the initial errors that induce large prediction errors for El Niño and present significant PB have the potential to possess a La Niña-like evolving mode and cause the El Niño to be underpredicted.

\section{Implications for ENSO predictions}

In the previous sections, we have revealed the initial errors that often cause summer PB for CP El Niño and spring PB for EP El Niño and explain why they always behave similar to a La Niña-like evolving mode and the corresponding physical mechanism. Concerning their spatial patterns, it can be noticed that they are mainly concentrated in a few regions with large anomalies. For CP El Niño, the CP-type-1 errors show large SST anomalies in the North Pacific with a VMlike structure but opposite signs, a dipolar structure in the equatorial Pacific, with positive anomalies in the upper layer of the central-eastern Pacific and negative anomalies in the lower layer of the western Pacific, and a SPMM-like pattern in the southeast Pacific. Such errors develop with a La Niñalike evolving mode and finally generate a cold bias of SST in the central and eastern tropical Pacific after a 12-month lead time. The CP-type-2 errors, however, are mainly located in the North Pacific and exhibit a VM-like SSTA pattern, and they also evolve with a La Niña-like mode but present the cold bias of SST in the central tropical Pacific at the 12-month lead time. The comparisons between CP-type-1 and -2 errors show that the initial SST uncertainties occurring in the North Pacific and possessing a VM-like structure tend to cause CP-El Niño events to be underestimated in terms of amplitude and even to be predicted as La Niña-like events but with cold centers in the central tropical Pacific, which therefore mainly influences the amplitude of SST in the central Pacific associated with CP-El Niño, whereas the initial sea temperature errors occurring in the equatorial Pacific and southeast Pacific have potential to cause the CP-El Niño to be predicted as a canonical La Niña-like event with a cold center in the eastern equatorial Pacific, which destroys the structure of CP-El Niño with the anomaly center in the central tropical Pacific and tends to cause the CP-El Niño to be predicted as a La Niña-like events with cold centers in the eastern equatorial Pacific. Therefore, we can state that the CP-type-2 errors mainly influence the intensity of CP-El Niño, whereas the CP-type-1 errors modulate 


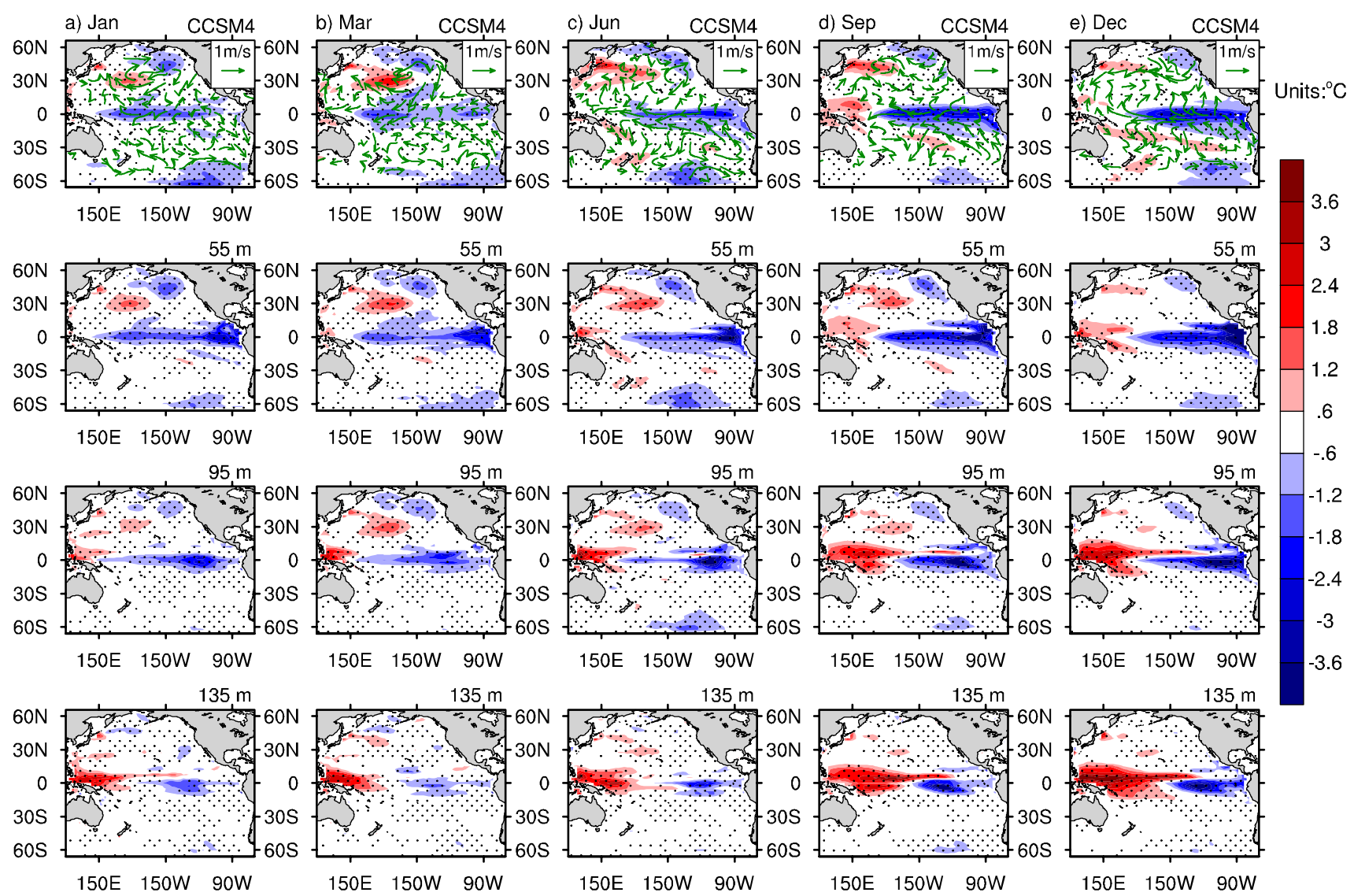

Fig. 14 As in Fig. 8, but for the EP-type-2 error for EP-El Niño

the structure of CP-El Niño in addition to the intensity and can possibly cause a CP-El Niño event to be predicted as a canonical La Niña event. These indicate that the initial uncertainties occurring in different regions may determine different aspects of CP-El Niño in predictions. From the above analysis, it is inferred that the CP-El Niño predictions should concern not only the accuracy of initial sea temperature in the tropical Pacific but also that in the North Pacific. The former is more crucial for better predictions of the structure of the CP-El Niño events besides intensity, and the latter is more important for better predictions of the intensity of the CP-El Niño events.

As for EP-El Niño, both EP-type-1 and -2 errors show large anomalies in the three regions of the northern Pacific, equatorial Pacific and southeastern Pacific. Furthermore, the EP-type-1 and -2 errors possess a similar structure to the CP-type-1 errors. However, the former presents the same signs as for CP-type-1, whereas the latter shows signs opposite those of CP-type-1. Despite this, both types of errors finally develop into a canonical La Niña-like cooling mode with the cold center in the central-eastern equatorial Pacific. That is, the EP-type-1 and -2 errors mainly influence the accuracy of the SST in the tropical central-eastern Pacific in predictions. Encouraged by the evolution of CP-type-2 error (which locates on the SST in the North Pacific with a VM-like mode and only induces SST errors in the central tropical Pacific), we infer that the prediction of EP-El Niño events in terms of intensity should be of more concern to the accuracy of the sea temperature in the tropical and southeast Pacific, whereas in terms of structure, increased attention should be paid to the accuracy of the sea temperature in the region covered by the VM-like mode in the North Pacific.

From the above discussion, it has been implied that the accuracy of the sea temperature in the tropical and southeast Pacific revealed by the CP-type-1 or the EP-type-1 (and -2) errors is more important for better predictions of the structure of CP-El Niño and the intensity of EP-El Niño, whereas the accuracy of the sea temperature in the region covered by the VM-like mode in the North Pacific is crucial for better predictions of the intensity of CP-El Niño and the structure of EP-El Niño. It is therefore clear that the accuracy should be improved for not only the sea temperatures in the tropical and southeast Pacific but also for those in the North Pacific, especially those in the subsurface layers of the western tropical Pacific and the surface layer of the southeast Pacific and in the region covered by the VM-like mode in the North 
Pacific, to effectively distinguish the types of El Niño events in predictions.

The above results infer that, besides tropical Pacific, the northern subtropical sea temperature uncertainties also play an important role in modulating CP-El Niño while the uncertainties occurring in the sea temperature in the southern subtropical Pacific area exert influences on the EP El Niño formulation. Vimont et al. (2014) indicated that the optimal initial conditions for CP ENSO includes the northern subtropical Pacific area while for EP ENSO includes southern subtropical Pacific area. Yu and Fang (2018) revealed that the seasonal footprinting mechanism is a key source of the ENSO complexity and is capable of importing extratropical influences on the tropical ENSO. Clearly, these previous studies indicated the importance of initial condition in the extratropical areas in distinguishing the types of El Niño, supporting our results. Particularly, the present study pointed out the accuracy of the sea temperature in the tropical and southeast Pacific is more important for better predictions of the structure of CP-El Niño and the intensity of EP-El Niño, whereas the accuracy of the sea temperature in the region covered by the VM-like mode in the North Pacific is crucial for better predictions of the intensity of CP-El Niño and the structure of EP-El Niño. Comparison between previous studies and the present study implies that the El Niño evolving and its error growth possess similar mechanism. Therefore, if one reduces the effect of initial errors on El Niño predictions by intensifying observations, these additional observations are also useful for identifying the precursor of El Niño and the skill of identifying the types of El Niño in predictions can therefore be improved. In fact, the validation tests to the results in the present study are under our investigation by using particle filter assimilation method. The preliminary results support our conclusions here.

\section{Summary and discussion}

In this study, an approach to data analysis for predictability is developed to investigate the internal variability problems of error growth dynamics associated with the season-dependent PB for CP- and EP-El Niño by using the monthly mean pi-Control data of six coupled models preselected from the CMIP5. The summer PB is revealed to occur in the CP-El Niño predictions, whereas the spring $\mathrm{PB}$ is shown to be aroused in EP-El Niño predictions. Two types of initial errors, denoted as CP-type- 1 and -2 errors, are found to frequently cause summer PB for CP-El Niño events. The CP-type-1 error presents an SST chain structure of negative-positive-negative-positive anomalies along the region from the northwestern Pacific and then the eastern tropical Pacific to the southeastern Pacific and a subsurface temperature dipolar structure of positive anomalies in the central-eastern equatorial Pacific and negative anomalies in the lower layers of the western equatorial Pacific. This error first undergoes an El Niño-like decaying mode and then changes to a growth phase of a La Niña-like event, finally triggering a cold bias of the SST with a cold center in the tropical central-eastern Pacific in December and causing the relevant CP-El Niño to be underpredicted, even likely to make the CP-El Niño be predicted into a La Niña-like event with the cold center in tropical eastern Pacific. The CP-type-2 error shows strong SST anomalies mainly in the northeastern Pacific, with negative values near the Alaska region and in the subtropics near Baja California and positive values in the central-north Pacific, bearing resemblance with the mode opposite to the VM-like one. Such an error evolves similar to a La Niña event and causes a cold bias of the SST but with the cold center located in the Niño4 area in December. Obviously, the CP-type-2 error mainly influences the intensity of CP-El Niño (i.e., the amplitude of Niño4 SSTA), even possibly causing the CP-El Niño to be predicted as a La Niña-like event but with a cold center in the central equatorial Pacific.

As for the EP El Niño events, we also obtain two types of initial errors (denoted as EP-type-1 and -2 errors) that frequently cause spring PB for EP-El Niño events. Both EPtype- 1 and -2 errors possess a structure very similar to $\mathrm{CP}$ type-1 errors, but EP-type-1 error has the same signs as the CP-type-1 error, whereas the EP-type-2 error possesses signs opposite to the CP-type-1 error. That is, EP-type-1 error and CP-type-1 error are almost the same in both structure and signs. However, we notice that they are superimposed on different types of El Niño. Nevertheless, they still undergo common dynamical behaviors. That is, they behave initially in an El Niño-like decaying mode and then transition to the growth phase of a canonical La Niña-like event. For EPtype- 2 error, the evolution is also similar to a canonical $\mathrm{La}$ Niña event but starts from a weak La Niña phase. Both EPtype- 1 and -2 errors finally cause large cold biases of the SST in the tropical central-eastern Pacific and mainly influence the intensities of EP-El Niño events.

From the above results, either CP-type- 1 and -2 errors for CP-El Niño or EP-type-1 and -2 errors for EP-El Niño finally develop into a La Niña-like mode during the mature phase of the El Niño. For this, the present study provides a mathematical interpretation and shows that the initial errors of large effect on prediction uncertainties for El Niño always tend to evolve into a La Niña-like mode. In addition, this study also provides useful implications for El Niño predictions. By tracing the evolution of the initial errors, we concluded that the initial sea temperature accuracy over the $\mathrm{VM}$ region in the North Pacific is more important for better predictions of the intensity of the CP-El Niño, whereas that in the subsurface layer of the west equatorial Pacific and the surface layer of the southeast Pacific is of more concern for 
better predictions of the structure of CP-El Niño. The better predictions of EP-El Niño events in terms of intensity are also shown to benefit from accurate initial sea temperatures in the subsurface layer of the west equatorial Pacific and the surface layer of the southeast Pacific. Encouraged by the evolution of the CP-type-2 error, the accuracy of the sea temperature in the region covered by the VM-like mode in the North Pacific, which is also one of the components of EP-type-1 and -2 errors for EP-El Niño, can favor the formation of a CP-El Niño and may therefore destroy the structure of EP-El Niño. Therefore, in the predictions of El Niño types, one should take care regarding initial sea temperature accuracy not only in the tropical Pacific but also in the subtropical Pacific, especially in the subsurface layer of the west equatorial Pacific, the surface layer of the southeast Pacific and in the region covered by the VM-like mode in the North Pacific.

The use of targeted observations to improve forecast skills of high-impact weather events has been explored in several field programs (Langland 2005; Mu et al. 2015). Given the high cost and huge difficulties of deploying observation arrays over the entire ocean, deploying observations in some key areas may be a more economical and efficient method, merely from the perspective of targeted observations with the aim of promoting prediction skills for weather or climate. In this study, it has been implied that the accuracies of the sea temperatures in the subsurface layer of the west equatorial Pacific, the surface layer of the southeast Pacific and in the region covered by the VM-like mode in the North Pacific are more important for predicting which type of El Niño will occur. To put it another way, we can say that the prediction of types of El Niño is more sensitive to the initial sea temperature errors in these areas. Therefore, if additional observations are deployed in these areas and then simulated in the model, the chance of the occurrence of large prediction errors may be reduced and even avoided; in particular, the type of El Niño could be effectively distinguished in predictions.

Mu et al. (2007) demonstrated that the PB for El Niño occurs in spring and summer, thus they named it spring PB. In the present study, we concern two different types of El Niño and identify that the CP-El Niño forecasting easily suffers from summer PB and EP-El Niño forecast more possibly suffers from spring PB. Such differences between the two studies may result from the measurement of initial errors and the concern of different types of El Niño. Mu et al. (2007) considered the initial errors in the whole tropical Pacific while the present study considers the initial errors at Niño 3 area for EP-El Niño and Niño 4 area for CP-El Niño, respectively. Samelson and Tziperman (2001) demonstrated that the El Niño forecasting suffers from growth phase PB. They indicated that the existence of a PB for ENSO is highly associated with the growth phase of El Niño conditions. In the present study, we stated that the spring PB for EP-El Niño and summer PB for CP-El Niño are also focused on the growth phase of El Niño and the unstable dynamical growth are most favorable for the error growth, finally triggering $\mathrm{PB}$. So the PB we found is not contradict to the growth phase PB proposed in Samelson and Tziperman (2001), and it especially focused on the details of the seasonal PB for both EP- and CP-El Niño events.

Our results also include that the prediction errors of the Niño4 SSTA associated with CP-El Niño grow significantly only in summer in all the models, whereas the prediction errors of the Niño3 SSTA associated with EP-El Niño grow considerably in spring and even in both spring and winter in some models. Furthermore, when we identify the comprehensive PB-related initial error, the inconformity among models more frequently occurs for EP El Niño events. Kim and $\mathrm{Yu}$ (2012) found that it is more difficult for the CMIP5 models to reproduce the observed EP-El Niño than the observed CP-El Niño, which may shed light on why the six models in the present study are shown to have a much larger spread for simulation of EP-El Niño predictability. Does this then indicate that it is much harder to successfully predict EP-El Niño in comparison with CP-El Niño in terms of these six models? This is a challenging question and ought to be explored in the future. Of course, from the result revealed in this study that the PB for EP-El Niño is stronger than that for CP-El Niño, it may show that it is more difficult to successfully predict EP-El Niño than CP-El Niño, even if the model is perfect. Tian and Duan (2015) corrected the Zebiak-Cane model to predict EP- and CP-El Niño events and showed that the EP-El Niño is more unpredictable than the CP-El Niño. For the present low skill in predicting CP-El Niño events (see the introduction), the reason could be more associated with the effect of model errors because most of the existing models cannot simultaneously produce both CPand EP-El Niño.

Tian and Duan (2015) took CP-El Niño into consideration and used the corrected Zebiak-Cane model to investigate the effect of tropical ocean uncertainties on CP- and EP-El Niño events predictions (also see Duan et al., 2018). They demonstrated that for both CP- and EP-El Niño, the initial sea temperature errors that have large effect on prediction uncertainties are concentrated in the central and eastern tropical Pacific and emphasized the importance of tropical sea temperature uncertainties in distinguishing the type of El Niño. In present study, we also emphasized here the importance of the accuracy of the sea temperature in the tropical Pacific in distinguishing the type of El Niño in predictions. Besides, we additionally focused on the extratropical influences on El Niño prediction uncertainties besides the tropical ones. Some studies also showed that the El Niño types are also related to other ocean basins such as the Atlantic basin (Ham et al. 2013; Dommenget 
and $\mathrm{Yu}$ 2017). Therefore, further investigation should be undertaken regarding the interaction between the Atlantic and Pacific Oceans and its contribution to the predictability of El Niño types. After this, conclusion of what on earth determines the type of El Niño may finally be made. It is expected that the prediction skill of El Niño type can therefore be greatly improved.

Acknowledgements This study was supported by the National Natural Science Foundation of China (Grant Nos. 41525017 and 41690124) and the National Programme on Global Change and Air-Sea Interaction (No. GASI-IPOVAI-06).

Open Access This article is distributed under the terms of the Creative Commons Attribution 4.0 International License (http://creativeco mmons.org/licenses/by/4.0/), which permits unrestricted use, distribution, and reproduction in any medium, provided you give appropriate credit to the original author(s) and the source, provide a link to the Creative Commons license, and indicate if changes were made.

\section{References}

Andrews ED, Antweiler RC, Neiman PJ, Ralph FM (2004) Influence of ENSO on flood frequency along the California coast. J Clim 17:337-348

Ashok K, Behera SK, Rao SA, Weng H, Yamagata T (2007) El Niño Modoki and its possible teleconnection. J Geophys Res 112:C11007

Barnston AG, Tippett MK, L'Heureux ML, Li S, Dewitt DG (2012) Skill of real-time seasonal ENSO model predictions during 2002-11: is our capability increasing? Bull Am Meteorol Soc 93:631-651

Bellenger H, Guilyardi E, Leloup J, Lengaigne M, Vialard J (2014) ENSO representation in climate models: from CMIP3 to CMIP5. Clim Dyn 42:1999-2018

Bjerknes J (1968) Atmospheric teleconnections from the equatorial Pacific. Mon Weather Rev 97:163-172

Bond NA, Overland JE, Spillane M, Stabeno PJ (2003) Recent shifts in the state of the North Pacific. J Geophys Res Ocean 30:2183

Chen D, Zebiak SE, Busalacchi AJ, Cane MA (1995) An improved procedure for EI Niño forecasting: implications for predictability. Science 269:1699-1702

Chen D, Cane MA, Kaplan A, Zebiak SE, Huang D (2004) Predictability of El Niño over the past 148 years. Nature 428:733-736

Chou C, Lo MH (2007) Asymmetric responses of tropical precipitation during ENSO. J Clim 20:3411-3433

Ding R, Li J, Tseng YH (2015a) The impact of South Pacific extratropical forcing on ENSO and comparisons with the North Pacific. Clim Dyn 44:2017-2034

Ding R, Li J, Tseng YH, Sun C, Guo Y (2015b) The Victoria mode in the North Pacific linking extratropical sea level pressure variations to ENSO. J Geophys Res Atmos 120:27-45

Dommenget D, Yu Y (2017) The effects of remote SST forcings on ENSO dynamics, variability and diversity. Clim Dyn 49:2605-2624

Duan W, Hu J (2015) The initial errors that induce a significant "spring predictability barrier" for El Niño events and their implications for target observation: results from an earth system model. Clim Dyn 46:1-17

Duan W, Wei C (2012) The 'spring predictability barrier' for ENSO predictions and its possible mechanism: results from a fully coupled model. Int J Climatol 33:1280-1292
Duan W, Liu X, Zhu K, Mu M (2009) Exploring the initial errors that cause a significant "spring predictability barrier" for El Niño events. J Geophys Res Ocean 114:C04022

Duan W, Li X, Tian B (2018) Towards optimal observational array for dealing with challenges of El Niño-Southern Oscillation predictions due to diversities of El Niño. Clim Dyn 51:3351-3368

Feng R, Mu M, Duan W (2014) Study on the "winter persistence barrier" of Indian Ocean dipole events using observation data and CMIP5 model outputs. Theor Appl Climatol 118:523-534

Ham YG, Kug JS (2012) How well do current climate models simulate two types of El Niño? Clim Dyn 39:383-398

Ham YG, Kug JS, Park JY, Jin FF (2013) Sea surface temperature in the north tropical Atlantic as a trigger for El Niño/Southern Oscillation events. Nat Geosci 6:112-116

Hendon HH, Eunpa L, Wang G, Oscar A, Debra H (2009) Prospects for predicting two flavors of El Niño. J Geophys Res 36:L19713

Hong L, Jin FF (2014) A Southern Hemisphere booster of super El Niño. J Geophys Res 41:2142-2149

Jeong HI et al (2012) Assessment of the APCC coupled MME suite in predicting the distinctive climate impacts of two flavors of ENSO during boreal winter. Clim Dyn 39:475-493

Jin FF (2000) An equatorial ocean recharge paradigm for ENSO. Part I: conceptual model. J Atmos Sci 54:811-829

Jin FF, Neelin JD, Ghil M (1994) El Niño on the devil's staircase: annual subharmonic steps to chaos. Science (New York, N.Y.) 264:70-72

Kao HY, Yu JY (2009) Contrasting eastern-Pacific and central-Pacific types of ENSO. J Clim 22:615-632

Kim ST, Yu JY (2012) The two types of ENSO in CMIP5 models. J Geophys Res 39:221-228

Kug JS, Jin FF, An SI (2009) Two types of El Niño events: cold tongue El Niño and warm pool El Niño. J Clim 22:1499-1515

Kug JS, Choi J, An SI, Jin FF, Wittenberg AT (2010) Warm pool and cold tongue El Niño events as simulated by the GFDL CM2.1 coupled GCM. J Clim 23:1226-1239

Langland RH (2005) Issues in targeted observing. Q J R Meteorol Soc 131:3409-3425

Larkin NK, Harrison DE (2005) On the definition of El Niño and associated seasonal average U.S. weather anomalies. Geophys Res Lett 32:435-442

Latif M et al (1998) A review of the predictability and prediction of ENSO. J Geophys Res Ocean 103:14375-14393

Lee T, Mcphaden MJ (2010) Increasing intensity of El Niño in the central-equatorial Pacific. J Geophys Res 37:1205-1215

Levine AFZ, Jin FF (2010) Noise-induced instability in the ENSO recharge oscillator. J Atmos Sci 67:529-542

Luo JJ, Masson S, Behera S, Shingu S, Yamagata T (2005) Seasonal climate predictability in a coupled OAGCM using a different approach for ensemble forecasts. J Clim 18:4474-4497

Mcphaden MJ (2015) Playing hide and seek with El Niño. Nat Clim Change 5:791-795

Mcphaden MJ, Zebiak SE, Glantz MH (2006) ENSO as an integrating concept in earth science. Science 314:1740-1745

Min Q, Su J, Zhang R (2017) Impact of the South and North Pacific meridional modes on the El Niño-southern oscillation: observational analysis and comparison. J Clim 30:1705-1720

Moore AM, Kleeman R (1996) The dynamics of error growth and predictability in a coupled model of ENSO. Q J R Meteorol Soc 122:1405-1446

Mu M, Xu H, Duan W (2007) A kind of initial errors related to "spring predictability barrier" for El Niño events in Zebiak-Cane model. J Geophys Res 34(3709):1-6

Mu M, Duan W, Chen D, Yu W (2015) Target observations for improving initialization of high-impact ocean-atmospheric environmental events forecasting. Natl Sci Rev 2:226-236 
Neelin JD (1991) The slow sea surface temperature mode and the fastwave limit: analytic theory for tropical interannual oscillations and experiments in a hybrid coupled model. J Atmos Sci 48:584-606

Qi QQ, Duan WS, Zheng F, Tang YM (2017) On the "spring predictability barrier" for strong El Niño events as derived from an intermediate coupled model ensemble prediction system. Sci China Earth Sci 60:1614-1631

Rasmusson EM, Wallace JM (1983) Meteorological aspects of the el Niño/southern oscillation. Science 222:1195-1202

Rayner NA et al (2003) Global analyses of sea surface temperature, sea ice, and night marine air temperature since the late nineteenth century. J Geophys Res Atmos 108:4407

Ren HL, Jin FF, Tian B (2016) Distinct persistence barriers in two types of ENSO. J Geophys Res 43:10973-10979

Ropelewski CF, Halpert MS (1987) Global and regional scale precipitation patterns associated with the El Niño/Southern oscillation. Mon Weather Rev 115:985-996

Samelson RM, Tziperman E (2001) Instability of the chaotic ENSO: the growth-phase predictability barrier. J Atmos Sci 58(23):3613-3625

Storlazzi CD, Griggs GB (1998) Influence of El Niño-Southern Oscillation (ENSO) events on the coastline of central California. J Coast Res. Special issue (No. 26):146-153

Tang Y et al (2018) Progress in ENSO prediction and predictability study. Natl Sci Rev 5:826-839. https://doi.org/10.1093/nsr/nwy10 5

Taylor KE, Stouffer RJ, Meehl GA (2012) An overview of CMIP5 and the experiment design. Bull Am Meteorol Soc 93:485-498

Tian B, Duan W (2015) Comparison of the initial errors most likely to cause a spring predictability barrier for two types of El Niño events. Clim Dyn 47:779-792

Timmermann A et al (2018) El Niño-Southern Oscillation complexity. Nature 559:535-545

Vimont DJ, Battisti DS, Hirst AC (2001) Footprinting: a seasonal connection between the tropics and mid-latitudes. J Geophys Res 28:3923-3926

Vimont DJ, Battisti DS, Hirst AC (2003a) The seasonal footprinting mechanism in the CSIRO general circulation models. J Clim 16:2653-2667

Vimont DJ, Wallace JM, Battisti DS (2003b) The seasonal footprinting mechanism in the Pacific: implications for ENSO. J Clim $16: 2668-2675$

Vimont DJ, Alexander MA, Newman M (2014) Optimal growth of Central and East Pacific ENSO events. Geophys Res Lett 41:4027-4034. https://doi.org/10.1002/2014g1059997

Wang C (2018) A review of ENSO theories. Natl Sci Rev 5:813-825. https://doi.org/10.1093/nsr/nwy104

Webster PJ (1995) The annual cycle and the predictability of the tropical coupled ocean-atmosphere system. Meteorol Atmos Phys 56:33-55

Webster PJ, Yang S (1992) Monsoon and ENSO: selectively interactive systems. Q J R Meteorol Soc 118:877-926

Weng H, Ashok K, Behera SK, Rao SA, Yamagata T (2007) Impacts of recent El Niño Modoki on dry/wet conditions in the Pacific rim during boreal summer. Clim Dyn 29:113-129
Xie SP, Philander SGH (1994) A coupled ocean-atmosphere model of relevance to the ITCZ in the eastern Pacific. Tellus 46:340-350

Xue Y, Cane MA, Zebiak SE, Palmer TN (1997) Predictability of a coupled model of ENSO using singular vector analysis. Part II: optimal growth and forecast skill. Mon Weather Rev 125:2043

Yeh S-W, Wang X, Wang C, Dewitte B (2015) On the relationship between the North Pacific climate variability and the central Pacific El Niño. J Clim 28:663-677

Yu JY, Fang SW (2018) The distinct contributions of the seasonal footprinting and charged-discharged mechanisms to ENSO complexity. J Geophys Res 45:6611-6618

Yu JY, Kao HY (2007) Decadal changes of ENSO persistence barrier in SST and ocean heat content indices: 1958-2001. J Geophys Res Atmos 112:125-138

Yu JY, Kim ST (2011) Relationships between extratropical sea level pressure variations and the central Pacific and eastern Pacific types of ENSO. J Clim 24(3):708-720

Yu JY, Duan W, Hui X, Mu M (2009) Dynamics of nonlinear error growth and season-dependent predictability of El Niño events in the Zebiak-Cane model. Q J R Meteorol Soc 135:2146-2160

Zebiak SE, Cane MA (1987) A model El Niño-Southern Oscillation. Mon Weather Rev 115:2262-2278

Zhang W, Jin FF, Li J, Ren HL (2011) Contrasting impacts of two-type El Niño over the Western North Pacific during boreal autumn. J Meteorol Soc Jpn 89:563-569

Zhang W, Jin FF, Ren HL, Li J, Zhao JX (2012) Differences in teleconnection over the North Pacific and Rainfall Shift over the USA associated with two types of El Niño during boreal autumn. J Meteorol Soc Jpn 90:535-552

Zhang H, Clement A, Nezio PD (2014) The South Pacific Meridional Mode: a mechanism for ENSO-like variability. J Clim 27:769-783

Zhang J, Duan WS, Zhi XF (2015) Using CMIP5 model outputs to investigate the initial errors that cause the "spring predictability barrier" for El Niño events. Sci China Earth Sci 58:1-12

Zhang W et al (2016) Unraveling El Niño's impact on the East Asian Monsoon and Yangtze River summer flooding. J Geophys Res 43:11375-11382

Zheng F, Yu J-Y (2017) Contrasting the skills and biases of deterministic predictions for the two types of El Niño. Adv Atmos Sci 34(12):1395-1403. https://doi.org/10.1007/s00376-017-6324-y

Zheng F, Zhu J (2010) Spring predictability barrier of ENSO events from the perspective of an ensemble prediction system. Glob Planet Change 72:108-117. https://doi.org/10.1016/j.glopl acha.2010.01.021

Zheng F, Fang X-H, Yu J-Y, Zhu J (2014) Asymmetry of the Bjerknes positive feedback between the two types of El Niño. Geophys Res Lett 41:7651-7657. https://doi.org/10.1002/2014GL062125

Publisher's Note Springer Nature remains neutral with regard to jurisdictional claims in published maps and institutional affiliations. 